EDUCACION EN DERECHOS HUMANOS: .EL DISCURSO DE LOS PROFESORES EN COLOMBIA

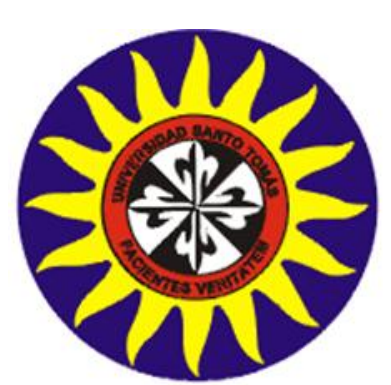

GIOVANNY FRANCHESCO SALCEDO CRUZ.

UNIVERSIDAD SANTO TOMAS

FACULTAD DE DERECHO

BOGOTA D.C.-COLOMBIA 



\section{EDUCACION EN DERECHOS HUMANOS: .EL DISCURSO DE LOS PROFESORES EN COLOMBIA}

$1994-2015$

\section{GIOVANNY FRANCHESCO SALCEDO CRUZ.}

Tesis de grado presentada para optar al título de Magister en Defensa de los Derechos Humanos ante las cortes y organismos internacionales

Directora:

Elsa Bonilla Piratova.

UNIVERSIDAD SANTO TOMAS

FACULTAD DE DERECHO

BOGOTA D.C.-COLOMBIA

2017 


\section{DEDICATORIA.}

A Sonia compañera incansable en la aventura de la vida, guerrera inagotable de la vida y quien me ha enseñado el significado del verdadero amor.

A Dante Atanael por su paciencia, aguante, lucidez e inquebrantable voluntad de vivir y sobre todo por hacerme entender que la bondad no se ha agotado en el mundo.

A mis cuñadas (Galia, Mónica y Manuela) por la invariable colaboración y por su presencia siempre incondicional.

A mi suegro Manuel por el apoyo y la imperecedera colaboración.

A mi madre quien siempre me acompaña desde la eternidad.

A todos ellos mi vida y mi amor. 


\section{AGRADECIMIENTOS.}

Agradecimiento a todas las personas que con sus aportes y reflexiones me han permitido madurar las ideas que a continuación se exponen y llevar a buen puerto este trabajo.

A mi esposa Sonia porque siempre me ha acompañado en este ejercicio académico, por sus consejos siempre a tiempo, sus meditaciones inquebrantables, adecuadas y siempre someras.

A la doctora Elsa que con paciencia y agrado ha contribuido a terminar con satisfacción este trabajo.

A la Universidad Santo Tomas por contribuir a generar espacios de reflexión permanentes sobre los Derechos Humanos, en una sociedad convulsa y siempre de afán, es bueno saber que por sus aulas caminan intelectuales preocupados por hacer de este mundo un lugar mejor para todos.

A la Secretaria de Educación del Distrito que ha permitido que muchos profesores profundicemos en los temas de nuestros intereses y que contribuirán a que la ciudad continúe liderando los procesos de calidad de la educación, siempre con un sentido humano y con la posibilidad de impactar en el presente y futuro de nuestra ciudad y la sociedad en general. 


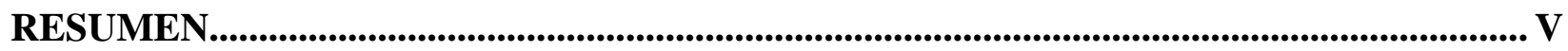

SUMMARY …..................................................................................................................................................VI

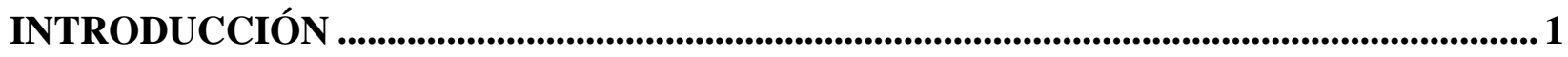

1. EXORDIO A PROPÓSITO DE LA EDUCACIÓN EN DERECHOS HUMANOS ..........5

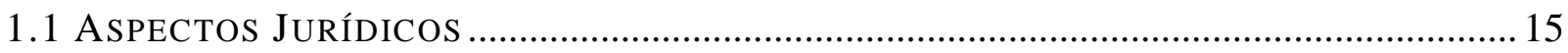

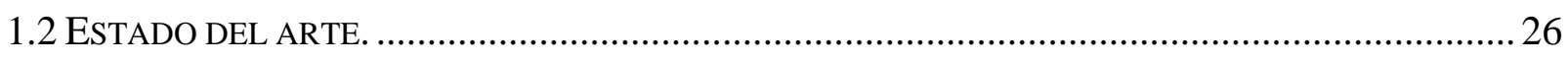

2. DISCURSO PEDAGÓGICO, ESCUELA Y DERECHOS HUMANOS..........................51

3- LA CONSTRUCCIÓN DEL DISCURSO DE LOS PROFESORES EN LA

EDUCACIÓN EN DERECHOS HUMANOS, DEBATES Y CONTROVERSIAS EN EL MAGAZÍN AULA URBANA Y LA REVISTA EDUCACIÓN Y CULTURA 1994- 201580

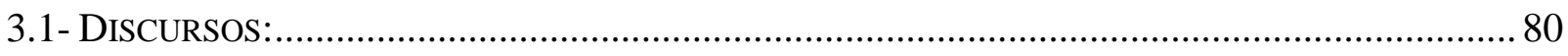

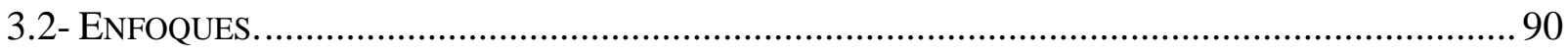

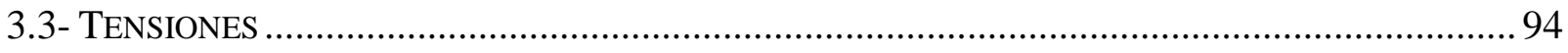

4- CONCLUSIONES. ...................................................................................................................................98

REFERENCIAS BIBLIOGRÁFICAS.........................................................................105 


\section{Resumen}

En el transcurso de esta investigación se analizaron los discursos elaborados por los educadores frente a la Educación en Derechos Humanos (EDH) desde la lectura crítica de la revista Educación y Cultura y el Magazín Aula Urbana, ambos órganos difusores del pensamiento de los profesores del país.

Se identificaron los mencionados discursos, con el propósito de considerar las perspectivas filosóficas, históricas, políticas, y culturales desde las cuales se aborda el trabajo frente a los Derechos Humanos que desarrollan los formadores en sus prácticas pedagógicas.

Finalmente se identificaron las características principales de las propuestas dominantes entre quienes tienen a su cargo la $\mathrm{EDH}$, para los jóvenes educandos del sector oficial de nuestro país; con la idea de generar una reflexión alternativa a las practicas pedagógicas dominantes en la escuela de hoy, la cual tiene que ver con un Discurso Crítico de la Educación en Derechos Humanos (DCEDH) que realice una mirada de esta desde una perspectiva ético-moral y propugne por generar reflexiones teórico-prácticas de los fundamentos de la teoría de los Derechos Humanos desde las aulas escolares.

Palabras Claves.

Educación, Democracia, Derechos Humanos, Análisis del Discurso, Educación en Derechos Humanos. 
Summary

In the course of this research, the discourses elaborated by the educators in relation to the Human Rights Education (EDH) were analyzed from the critical reading of the magazine Education and Culture and the Magazine Aula Urbana, both organs diffusers of the thought of the teachers of the country.

The mentioned discourses were identified, with the purpose of considering the philosophical, historical, political, and cultural perspectives from which the work against the Human Rights that the educators develop in their pedagogical practices.

Finally, we identified the main characteristics of the dominant proposals among those in charge of the ED, for the young students in the official sector of our country; With the idea of generating an alternative reflection to the pedagogical practices dominant in today's school which has to do with a Critical Discourse on Human Rights Education (DCEDH) that takes a look at this from an ethic-moral perspective and proposes For generating theoretical-practical reflections of the foundations of the theory of Human Rights from school classrooms.

Keywords.

Education, Democracy, Human Rights, Speech Analysis, Human Rights Education 


\section{Introducción}

La presente investigación tiene como objetivo analizar el discurso que han edificado los maestros en torno a la Educación en Derechos Humanos (EDH) teniendo como fuentes principales la revista Educación y Cultura y el magazín Aula Urbana. La pregunta que guía este trabajo tiene que ver con ¿Cómo se ha configurado el Discurso frente a la educación en Derechos Humanos, por parte de los profesores? La cual surgió como parte de la experiencia en la práctica pedagógica como profesor de Ciencias Sociales de un colegio público de Bogotá, en el cual se realiza el trabajo en Derechos Humanos desde una visión jurídica, que en muchas ocasiones aporta poco a los estudiantes ya que la asumen como una clase más de la que hay que aprender ciertas respuestas para repetir en los exámenes y no como un compromiso ético y moral para con ellos mismos, sus comunidades y la sociedad en general y gracias a la maestría en Defensa de los Derechos Humanos ante cortes y organismos internacionales que comencé en el año 2013, en la Universidad Santo Tomas y que hace parte de los programas de la Secretaria de Educación del Distrito para cualificar y actualizar las practicad pedagógicas de los educadores que hacen parte de la planta del distrito.

En lo que tiene que ver con la metodología, esta investigación se inscribe como un ejercicio de Análisis del Discurso (AD) el cual se considera como un aporte teórico al interior de las Ciencias Sociales que conduce a la transdisciplinariedad, con el fin de estudiar de manera sistemática el discurso tanto escrito como hablado; al interior de este aporte teórico y metodológico se considera el discurso como una forma por excelencia de la interacción social, política, histórica, cultural, económica y filosófica que involucra tanto a los seres humanos como a su contexto. 
En el Análisis del Discurso (AD), se despliegan tres fases que nos han permitido comprender de manera más adecuada el discurso labrado por los profesores frente a la Educación en Derechos Humanos (EDH); una de carácter teórico en la cual se ponen en juego los principios fundamentales que guían el estudio; una fase analítica en la que se consideran los hallazgos facticos en torno a los discursos que los educadores construyen frente a la (EDH) y una etapa practica en la cual se proponen conclusiones acerca de los discursos analizados a la luz del análisis y la teoría.

La elección de la revista Educación y cultura y el magazín Aula Urbana obedeció a que en ambos medios de comunicación escriben habitualmente profesores y algunas de las discusiones que en ellos se han sostenido redundan en los procesos pedagógicos y las prácticas de aula de los educadores, con lo cual se podría rastrear en ellas los discursos elaborados por los maestros con respecto a la EDH.

Consideramos que la EDH, ha sido la estrategia privilegiada por el Estado para mejorar los índices de cumplimiento de políticas frente al respeto y la práctica de los Derechos Humanos en el país. Los centros educativos han contribuido y en la mayoría de ocasiones los índices no han mejorado; consideramos que se debe proponer un giro en la manera en la que la mayoría de educadores han vislumbrado la dificultad con la anuencia del Estado y es considerar que la EDH es un problema de masificación de los contenidos de los instrumentos internacionales que ha suscrito en Estado y que se debe propiciar espacios en los cuales la cuestión se considere desde un punto de vista ético y moral ya que es desde allí como se podría impactar de manera más contundente la cultura escolar.

En este sentido el texto presenta en su primer capítulo una reflexión acerca de la manera en la que se ha desarrollado la EDH en el país; cuales fueron las preocupaciones que ocuparon a 
sus promotores y las circunstancias por las cuales la primera etapa de su configuración fue asumida desde los sectores no formales de la educación. Así mismo se considera el camino que ha recorrido la EDH para convertirse en un discurso asumido por un amplio sector de la educación formal, desde una mirada mayoritariamente jurídica y defendida por el Estado, lo cual ha dificultado la masificación de propuestas pedagógicas alternativas que pretenden educar a los jóvenes desde una visión más compleja; ubicando el asunto de los Derechos Humanos desde lo ético y moral; para terminar se presentan los antecedentes jurídicos a nivel internacional, como nacional en lo que tiene que ver con la EDH y como estos se entrelazan con los hechos que condujeron a establecer la necesidad de posesionar el tema al interior de la sociedad.

En el segundo capítulo se presentan los principios teóricos y metodológicos sobre los cuales descansa la investigación y se analizan las tensiones más evidentes que se producen al interior de los debates que allí se plantean, en este mismo sentido se consideran los objetivos y las preguntas que guían nuestra reflexión.

El tercero está dedicado a analizar el discurso producido por los profesores en las revistas Educación y Cultura editada por la Federación Colombiana de Educadores (FECODE) y el magazín Aula Urbana, del Instituto para la Investigación Educativa y el Desarrollo Pedagógico (IDEP), en este hemos recogido las discusiones que caracterizan la EDH, en lo que tiene que ver con los postulados filosóficos, históricos, políticos y culturales; resaltamos los aspectos metodológicos que proponen los educadores para realizar el trabajo que se debe ejecutar en lo que tiene que ver con la promoción y practica de los Derechos Humanos al interior de los escenarios escolares. 
Por otra parte consideramos los aspectos más relevantes en las propuestas que conciben los profesores y analizamos las tensiones que subyacen al discurso que se ha construido desde las prácticas profesorales y que se consolida en los espacios educativos.

Finalmente hemos propuesto unas conclusiones que hacen referencia al proceso de investigación, en ellas consideramos los aportes tanto teóricos como metodológicos que el trabajo proporciona a la $\mathrm{EDH}$, así como el impacto de la misma en las practicas pedagógicas de los profesores y que tipo de investigaciones podrían realizarse o que campos quedan abiertos para la discusión en lo que tiene que ver con la EDH en Colombia. 


\section{Exordio a Propósito de la Educación en Derechos Humanos}

El presente texto tiene como finalidad dar cuenta de cuales han sido los caminos que la Educación en Derechos Humanos ha tomado en Colombia y mostrar en qué estado de desarrollo se encuentra este tema a nivel de los profesores; es decir, se busca mostrar cuales han sido las discusiones y las vías que han seguido los educadores en cuanto a la Educación en Derechos Humanos (EDH en adelante); si existe un Discurso Crítico de ésta, elaborado por los profesores, que rutas metodológicas han establecido y cuál es el estado actual de la discusión en el país

La discusión sobre el derecho a la educación y lo que este implica en cuanto obligaciones para los Estados tuvo un amplio desarrollo, en el Informe presentado por la Relatora especial de las Naciones Unidas para el derecho a la Educación Katarina Tomasevski (2003); quien concluye que las obligaciones que se le atribuyen a los Estados por razón del derecho a la educación se pueden agrupar teniendo en cuenta un esquema de cuatro " $A$ " que se traduce en asequibilidad, acceso, aceptabilidad y adaptabilidad; considerando que la garantía del derecho se obtiene cuando se promueven estas cuatro variables que permiten hablar de una educación no solo garantizada, sino de calidad y que es labor de los Estados contribuir a que las políticas públicas tiendan a su desarrollo en lo que les corresponde.

Por otro lado existe en los tratados, mediante los cuales los Estados asumen compromisos jurídicos, la intensión explícita de comprender la EDH, como un derecho en sí mismo, lo cual va más allá del cumplimiento o no del derecho a educarse y toca de lleno con los fines mismo del acto educativo y tiene que ver con la dignidad humana como proyecto de vida; la EDH implica que el centro del proceso de enseñanza aprendizaje no sean más los conocimientos científicos, técnicos o de cualquier otra índole por sí mismos, sino como esos conocimientos le permiten al 
ser humano, propiciar los escenarios educativos para realizar proyectos de vida viables y dignos. Implica que la escuela debe ser ante todo un escenario profundamente democrático y en el cual las niñas, niños y jóvenes puedan comprender la profundidad y la relevancia que debe tener la democracia para la vida digna de todos los seres humanos.

Es en este sentido cuando cobra vida y preeminencia disponernos a analizar el contenido de los discursos de los profesores frente al ejercicio de educar para y por los Derechos Humanos, no solo como poseedores de un conocimiento científico; sino como facilitadores de una educación en Derechos Humanos que transforme la escuela, la vida y la sociedad en su conjunto.

De esta manera comprender la EDH, como un derecho especifico y diferenciado del derecho a la educación y su profunda trascendencia en el contexto de los colegios, es que se plantea la discusión acerca de ¿cuál es el contenido de los discursos que los profesores han elaborado sobre la educación en Derechos Humanos (EDH)?, ya que es necesario entender como este discurso permea las practicas diarias en la escuela de hoy.

En el discurso oficial colombiano ha estado presente la cuestión de los Derechos Humanos desde tiempo atrás, fue en la presidencia de Alfonzo López Michelsen (1974-1978) cuando el país ratificó la mayor parte de acuerdos, resoluciones y en fin los instrumentos internacionales para la protección y defensa de los Derechos Humanos y sin embargo, fue con la llegada del gobierno de Julio Cesar Turbay Ayala (1978-1982), cuando este tema comenzó a adquirir mayor relevancia a nivel nacional; en 1979, se expidió el decreto que estableció el llamado "estatuto de seguridad" que pretendía contrarrestar a los grupos guerrilleros, que habían aparecido una década y media antes con las banderas de la revolución socialista. Según Olarte Niño (2008); 
Con el estatuto le entregaron amplias facultades a los militares para el juzgamiento de civiles involucrados en actividades guerrilleras, se incrementaron las penas para el secuestro y se modificó la tipología penal de la sedición, haciéndola más amplia. Igualmente el tiempo de detención preventiva se extendió. (p.21).

Lo cual contribuyo a una radicalización de las oposiciones al gobierno de turno y represión a todas las formas de protesta popular. Las desapariciones, las torturas, los asesinatos y la persecución de intelectuales y defensores de los Derechos Humanos condujeron a que comenzara a condensarse un movimiento en pro de la defensa de los Derechos Humanos en el país. En este sentido vale la pena recordar las palabras de Manuel Restrepo Yusti (2008) cuando afirma que;

La Inquietud por el rumbo del gobierno hizo consolidar un fenómeno escaso en la cultura política colombiana, pero tampoco ausente en los momentos de crisis: un sentimiento de unidad e indignación...que confluyo en la idea de hacer un llamado al foro Nacional por los Derechos Humanos. (p.106).

La aparición del tema de los Derechos Humanos en la escena pública colombiana pasaría entonces por hacer un arduo trabajo de concienciación de la libertad como principal forma de respeto y practica de los derechos y hacer una pedagogía de esto, fue una tarea emprendida por intelectuales, profesores, miembros de organizaciones internacionales de Derechos Humanos y defensores de los mismos y el escenario que se privilegio fue la educación no formal; es decir que en las escuelas y universidades no se trabajó durante este período formalmente el tema, sino que este se dejó para los espacios sindicales, de organizaciones de víctimas, intelectuales y organizaciones de base. 
A finales del decenio de los setenta, se crearon en Colombia una serie de organizaciones que buscaban contribuir con la alfabetización no solo a nivel de los estudios primarios, sino apoyar la conciencia política de los sectores más vulnerables de la nación colombiana; en este sentido se pretendía; "la participación y liberación en consonancia con las corrientes políticas defensoras de los Derechos Humanos, a consolidar de los Estados democráticos, y al desarrollo económico capitalista que proveyera la satisfacción de las necesidades socioeconómicas de la mayoría de la población” (Sánchez Ochoa, 2014, p. 55).

Entre las principales experiencias en el decenio de los setenta podemos hablar de la llamada “educación propia” del Consejo Regional Indígena del Cauca (CRIC) que desde su fundación en 1971, se propuso; "Formar profesores bilingües para educar de acuerdo con la situación de los indígenas y en sus respectivas lenguas" (Bolaños y Tattay 2013. p.65), para los indígenas la escuela debería convertirse en una expresión más de la lucha de las comunidades y posibilitar su organización y la toma de conciencia por parte de los miembros de la misma, en este sentido los profesores se convertían en los promotores de acciones que afirmaran la pertenencia a las comunidades y facilitadores en un proceso de recuperación de la cultura de los pueblos ancestrales; esto lo podemos corroborar cuando afirman que la escuela debe;

ser pilar para sostener las recuperaciones de tierras y demás derechos sociales que se reclaman; acordar que la selección de los maestros se realice por las mismas comunidades; promover que las escuelas bilingües deben ser semilleros para revitalizar las culturas; incentivar a la comunidad para que participe en la orientación de las actividades escolares; trabajar conjuntamente para que en la escuela se enseñe lo de adentro y lo de afuera de manera crítica; motivar a los niños para que se queden en las comunidades y le aporten sus saberes y conocimientos; desarrollar procesos educativos y 
escolares que no partan del currículo oficial, sino de la construcción colectiva de nuevos programas de estudio; que privilegien la enseñanza tanto en la lengua indígena como en el castellano (Bolaños y Tittay.2013,p.67).

No hubo aportes desde la pedagogía y los profesores encargados de impartir los conocimientos a los educandos no desarrollaron metodologías, contenidos, no dieron discusiones sobre el carácter universalista o no de los Derechos Humanos y si es posible o no educar en tan delicada cuestión en las aulas y mucho menos en las cuestiones de cambios de paradigmas pedagógicos que implicaría una educación en Derechos Humanos para un país carente del respeto por las opiniones políticas, religiosas o culturales de sus habitantes.

Las experiencias aisladas y fragmentadas en muchas ocasiones comenzaron a conocerse en los ochentas y fue mediante las prácticas asociadas a la teología de la liberación, la educación popular y desde las propuestas de investigación alternativas como la Investigación Acción Participación (IAP) como en diversos espacios académicos, populares y políticos, comenzó la travesía de la educación en Derechos Humanos,(EDH) desde el trabajo popular y más asociado al sindicalismo, al trabajo barrial y a la exigibilidad en el cumplimiento de los mismos; es decir, desde la educación no formal e informal se dieron los primeros pasos hacia una educación que contemplará el trabajo en Derechos Humanos, como espacio de debate y consolidación de propuestas transformadoras de la realidad y del país mismo de quienes se encontraban involucrados.

A comienzos de los ochentas nació la Red de Educación Popular entre Mujeres, que desde sus inicios le apunto a desarrollar una educación feminista que diera cuenta de los abusos y maltratos a los que se veían sometidas las mujeres en los diversos escenarios públicos y privados del país, así mismo mostrar la contradicción existente en los movimientos sociales en los que se 
encontraba enquistada una visión patriarcal, y como a pesar de las luchas hombres y mujeres no eran tratados como iguales. De allí surgió la perspectiva de la "educación popular entre mujeres", que luego se constituye en "Educación Popular Feminista". Al respecto las investigadoras Imelda Arana y María Rapacci (1993), consideran que el enfoque feminista dentro de la educación popular es fundamental ya que este;

Cuestiona la lógica de dominación establecida por los sistemas de educación tradicionales y promueven activamente, la descolonización cultural, partiendo de un diálogo de saberes en el que la relación teoría-práctica permite y favorece la identificación y valoración de los conocimientos que los pueblos y las mujeres van creando en el devenir histórico. (p.83).

La fuerza que los movimientos populares le imprimió a la Educación en Derechos Humanos (EDH) durante los decenios de los setenta y ochenta, estuvo acompañada de las reflexiones pedagógicas y metodológicas; los principales aportes llegaron de la Pedagógica para la liberación de Freire y de las corrientes activas y críticas, siempre con la idea de tomar la realidad de los involucrados en el proceso de enseñanza como punto de partida y considerando que el profesor era el mediador entre las comunidades y el conocimiento, en ningún caso la educación puede considerarse un vehículo de dominación o subordinación; es más bien todo lo contrario, si esta no tiene como objetivo principal liberar las mentes y los cuerpos de las personas y permitir que el conocimiento que tienen las comunidades salga a flote y les permita transformar la realidad, esta no serviría para nada. En este sentido es una educación altamente comprometida con el cambio social y politizada, pero no se subordina la pedagogía a la política, sino que la primera permite la realización y comprensión de la segunda y esta no sería posible sin la conciencia y claridad que asumen los individuos gracias a la pedagogía. 
Los países del cono sur a finales de la década de los ochentas y en los primeros años de los noventas, volvieron a apalear a sistemas democráticos de representación política, luego de años de dictaduras, lo cual impactó de manera amplia al resto del continente; en materia de educación en Derechos Humanos (EDH) la educación popular y la escuela formal fueron fundamentales en la reconstrucción del tejido social que los atropellos y excesos de las dictaduras habían fracturado. A pesar que muchas leyes de perdón y punto final, se proclamaron con el fin de no hacer memoria sobre lo que había pasado durante el tiempo de las dictaduras; fueron las organizaciones de la sociedad civil y de base junto a algunos educadores del sector formal quienes de manera casi intransigente se dedicaron a escudriñar desde el escenario educativo la memoria como fuente de sanación y de reconstrucción de los proyectos de vida de las comunidades.

La Organización de las Naciones Unidas (ONU) designo el decenio 1995-2004, como el de la educación para y por los Derechos Humanos con el presupuesto de que es la educación la que puede intervenir en los escenarios cotidianos de las personas y por ende cambiar la cultura de negación y vulneración de los Derechos Humanos alrededor del mundo. Por ello, muchos países consolidaron carreras y currículos para trabajar la educación en Derechos Humanos $(\mathrm{EDH})$ desde los escenarios formales, en Colombia se tejieron esfuerzos en diversos espacios académicos, políticos e institucionales con el fin de mostrar las experiencias que en esta materia se desarrollaban en el país y desde allí implementar unas políticas públicas estatales que permitieran hacer realidad el mandato de las Naciones Unidas.

A pesar de los avances la década de los ochentas se cerraría con un saldo en rojo en materia de reflexiones sobre la educación en Derechos Humanos, (EDH) desde los escenarios formales de la enseñanza y uno podría decir que se dejó para la educación popular un terreno que 
ella misma había abonado y explotaba a su antojo. Pocos esfuerzos institucionales y apenas unas experiencias aisladas de proyectos de educadores que junto a sus educandos y algunos miembros de la comunidad educativa se empeñaban en no dejar morir, iniciativas como los consejos estudiantiles o de maestro en pos de dar un vuelco a la educación formal colombiana. Desde esta lógica tiene relevancia el Movimiento Pedagógico, que desde 1982 llevo su reflexión ya no solo a la necesidad de lucha y conquista de derechos para los miembros del magisterio colombiano; sino además a pensar la educación y a plantear algunas de las reformas que más adelante se consolidarían en la llamada ley 115 “Ley General de Educación” que desde1994, pretendió proporcionar los recursos y los escenarios en la escuela para transformar la sociedad y desarrollar el espíritu de la Constitución Política que unos años antes se había expedido y que le proporcionaba a las instituciones de educación las herramientas para entrar con fuerza a educar en y para los Derechos Humanos a la juventud colombiana desde los escenarios formales.

Las experiencias de los procesos de paz con el EPL, el M19 y otros grupos guerrilleros, la consolidación en el escenario político de lo que se podría llamar la Sociedad Civil con el auge de movimientos sociales como el de la séptima papeleta, la construcción de un nuevo pacto social expresado en la Constitución Política de 1991, la vuelta de los países suramericanos a la democracia y la declaración de la década 1995-2004 por parte de las Naciones Unidas como el decenio de los Derechos Humanos, marcaron un nuevo rumbo en la educación por y para los Derechos Humanos en América Latina y en Colombia; en este sentido la educación formal fue uno de los escenarios privilegiados por el cual se trazó el rumbo de esta nueva educación y desde allí las escuelas se convirtieron en las promotoras de los adelantos que en materia de educación en Derechos Humanos (EDH) se desarrollaron en la Constitución Política y sus profesores en las voces para la comprensión y difusión de estas políticas que buscaban transformar el país. 
Los procesos de paz con las guerrillas durante los gobiernos de Belisario Betancourt y Virgilio Barco; y cuyo colofón fue la reinserción de los miembros del EPL y el M-19, también contribuyeron a que desde el escenario de la educación formal se impulsaran iniciativas tendientes al trabajo de los Derechos Humanos desde las aulas escolares, mayores procesos de democratización de la escuela, del currículo y en fin de la educación como un sistema de reproducción social, se hicieron posibles con el concurso de profesores que ya habían emprendido el camino de educar en derechos.

La Colombia de finales del decenio de los ochentas, era una sociedad urbana, que había madurado lo suficiente como para dar vida a una de las experiencias más reveladoras de su madurez política "el movimiento de la séptima papeleta" que desde diversos escenarios exigió a la clase política un nuevo pacto social que estuviera a tono con los cambios por los que pasaba el país y desde allí se propuso realizar una constituyente que diera una bitácora renovadora del pacto entre la sociedad y el Estado a través de la Constitución Política de 1991, cargada de derechos y garantías, que condujeran al país a superar las contradicciones que lo habían sumido en la guerra que por esos días se vivía. Este fue el momento fundamental a la hora de trabajar el tema de la Educación en Derechos Humanos (EDH), por la enorme importancia que ellos cobraron y por los instrumentos que la Constitución consagraba. En este mismo escenario el llamado Movimiento Pedagógico, proponía una reforma a la educación, desde los educadores en la cual el trabajo con los Derechos Humanos fuera el centro del debate político en las escuelas de todo el territorio nacional.

Con la expedición de la Ley General de Educación de 1994, la escuela se convirtió en el escenario por excelencia para el trabajo en la educación para y por los Derechos Humanos, siguiendo los mandatos de la Constitución la cual consagro que: "la educación formará al 
colombiano en el respeto a los Derechos Humanos, la paz y la democracia" (Const; 1991, Art.67), lo cual contribuyo a que se volcaran muchos de los recursos (materiales e intelectuales) a la atmósfera escolar, con el fin de hacer realidad el mandato constitucional y con ello se abrió todo un "nuevo" escenario para la educación y para los educadores que tenía que ver con la democratización y participación de los diferentes actores (estudiantes, padres y madres de familia, profesores y demás miembros de la comunidad) en las decisiones que tomaban las instituciones educativas y que los involucraban de distintas maneras.

Con la expedición de las diversas leyes que desarrollaron el espíritu de la Constitución Política, en materia de educación en Derechos Humanos en el ámbito de lo formal se han trabajado mucho los aspectos formales y jurídicos de estos, pero la discusión sobre lo que implica una sociedad que respete y practique los Derechos Humanos, las profundas transformaciones pedagógicas que ello implica, la enorme capacidad para intervenir en los problemas que afectan a las comunidades a todos los niveles y las discusiones del orden filosófico que implican tener una posición teórica sobre que son y para qué sirven los Derechos Humanos y para que educar en ellos y desde que postura teórica se debe parar la escuela a la hora de emprender su estudio y sobre todo su práctica, se han dejado de lado y es más, a ellas pareciera que se les saca el cuerpo, privilegiándose los aspectos netamente formales y con ello restándole poder a una teoría que no puede perder su carácter revolucionario y trasformador a la vez que reconoce sus dificultades innatas, porque siguen existiendo voces que se resisten a ellos y los consideran nada más que las nuevas formas de reproducción y dominación de la sociedad occidental sobre los pueblos que no comparten esta teoría.

En este escenario en el que nos moveremos en esta investigación queremos pues dar cuenta de ¿cuáles son los discursos que han elaborado los profesores para ocuparse, desde las aulas de 
clase de la educación en Derechos Humanos?; ¿cuáles son las discusiones tanto filosóficas, como pedagógicas y metodológicas que se dan al comenzar a transitar por los caminos de la educación en Derechos Humanos? o si por el contrario; no reviste importancia y simplemente se dedican a trasmitir conocimientos formales sobre los Derechos Humanos, como si se tratara de una serie de temas que no requieren tratamientos especiales por el carácter valórico que ellos representan.

\subsection{Aspectos Jurídicos.}

Hablar de educación en Derechos Humanos (EDH) en Colombia, es comenzar a desatar el nudo gordiano de la historia nacional de los últimos cincuenta años, es reconstruir los esfuerzos que muchas y muchos han desarrollado por mejorar la vida de los colombianos en general y es sobre todo hacer un reconocimiento del arrojo que los defensores y defensoras de Derechos Humanos han tenido y como con sus prácticas han moldeado la vida y sacado adelante un tema que por su complejidad puede ser difícil en este país.

La edificación de una política pública para la educación en Derechos Humanos (EDH) se encuentra sustentada en las declaraciones, acuerdos y convenciones internacionales que desde la aparición de la Declaración Universal de los Derechos Humanos; se ha preocupado por desarrollar las estrategias suficientes y necesarias que tiendan a desplegar en el mundo entero una cultura de respeto y practica de los Derechos Humanos, que garantice la paz, la convivencia y la vida digna para todos. En este sentido la Declaración afirma que;

Proclama la siguiente Declaración Universal de Derechos Humanos como ideal común por el que todos los pueblos y naciones de la tierra deben esforzarse, a fin de que tanto los individuos como las instituciones, inspirándose constantemente en ella, promuevan, mediante la enseñanza y la educación, el respeto a estos derechos y libertades, y 
asegurara, por medidas progresivas de carácter nacional e internacional, su reconocimiento y aplicación universales y efectivos. (UNESCO. 2008 Santiago. Preámbulo)

El texto está reconociendo desde su entrada la importancia que tiene la educación en la difusión de los Derechos Humanos y en el propósito de hacer del mundo un lugar más justo para todos. La Declaración Universal considera que la educación es un derecho al cual todos los seres humanos deben poder acceder y que ella debe tener un carácter de obligatoriedad al menos en su ciclo básico, mientras que la técnica y la profesional deben ser generalizadas en lo más posible, por esta misma línea se considera:

La educación tendrá por objeto el pleno desarrollo de la personalidad humana y el fortalecimiento del respeto a los Derechos Humanos y a las libertades fundamentales; favorecerá la comprensión, la tolerancia y la amistad entre todas las naciones y todos los grupos étnicos o religiosos; y promoverá el desarrollo de las actividades de las Naciones Unidas para el mantenimiento de la paz. (UNESCO. 2008 Santiago, Art.26 Num.2)

Es decir que a partir este artículo y algunos de los considerandos de la introducción la Organización de las Naciones Unidas; desde la proclamación de su documento base contemplaba ya la educación en Derechos Humanos (EDH) como una de las columnas vertebrales del cambio cultural a nivel mundial y así lo ha venido demostrando a través de las diversas convenciones que han dotado de sentido el cuerpo de los derechos de diferentes grupos vulnerados y vulnerables asociándolos a la educación en Derechos Humanos y generando con ello obligaciones para los Estados miembros. 
La Declaración Americana de los Derechos y deberes del Hombre, firmada en Bogotá en 1948, considera, que la educación "debe estar inspirada en los principios de libertad, moralidad y solidaridad humanas” (OEA. Declaración; 1948. Art.13) y al ser un documento de carácter vinculante obliga al Estado colombiano a proveer los medios para que las funciones principales de la educación se hagan realidad de manera progresiva.

De otro lado como lo establece la Declaración de los Derechos del Niño en su principio 7, el niño tiene derecho a recibir educación, que será gratuita y obligatoria por lo menos en las etapas elementales. Se le dará una educación que favorezca su cultura general y le permita, en condiciones de igualdad de oportunidades, desarrollar sus aptitudes, su juicio individual, su sentido de responsabilidad moral y social y llegar a ser un miembro útil de la sociedad.

En este sentido la Convención sobre los derechos del Niño, considera como un deber del Estado dar educación a las niñas, niños y adolescentes al menos en los conocimientos básicos y que los propósitos de la educación deben ser en caminados a desarrollar la personalidad, las aptitudes y la capacidad mental y física del niño hasta el máximo de sus posibilidades. Los principios consagrados en la Carta de las Naciones Unidas en sus Arts. 28 y 29 insiste en la necesidad de Inculcar al niño el respeto de sus padres, de su identidad cultural, su idioma y sus valores, de los valores nacionales del país en que vive, del país de que sea originario y de las civilizaciones distintas de la suya; reconoce además que se debe preparar al niño para asumir una vida responsable en una sociedad libre, con espíritu de comprensión, paz, tolerancia, igualdad de los sexos y amistad entre todos los pueblos, grupos étnicos, nacionales y religiosos.

Por su parte el Pacto Internacional de derechos Económicos, Sociales y Cultural adoptado por la Asamblea General de las Naciones Unidas en 1966 Arts.13-14 y que entro en vigor un decenio después y el cual es reafirmado en el Protocolo de San Salvador adicional a la 
Convención Americana de Derechos Humanos en 1988, al referirse a la relación que existe entre el derecho a la educación y los Derechos Humanos considera que los Estados parte en dicho Protocolo han de convenir en que la educación deberá orientarse hacia el pleno desarrollo de la personalidad humana y del sentido de su dignidad fortaleciendo el respeto por los Derechos Humanos, el pluralismo ideológico, las libertades fundamentales, la justicia y la paz. Conviniendo asimismo, en que la educación debe capacitar a todas las personas para participar efectivamente en una sociedad democrática y pluralista.

En concordancia con lo anterior y con el fin de contribuir, la Convención Internacional sobre la Eliminación de todas las Formas de Discriminación Racial, considero el papel de la educación en los siguientes términos:

Los Estados partes se comprometen a tomar medidas inmediatas y eficaces, especialmente en las esferas de la enseñanza, la educación, la cultura y la información, para combatir los prejuicios que conduzcan a la discriminación racial y para promover la comprensión, la tolerancia y la amistad entre las naciones y los diversos grupos raciales o étnicos, así como para propagar los propósitos y principios de la Carta de las Naciones Unidas, de la Declaración Universal de Derechos Humanos, de la Declaración de las Naciones Unidas sobre la eliminación de todas las formas de discriminación racial y de la presente Convención. (ONU.1965, Art.7).

A sí mismo la Convención Interamericana para la Eliminación de todas las Formas de Discriminación contra las Personas con Discapacidad, contempla la obligación de los Estados parte para acabar con los estereotipos que afectan a las personas en condición de discapacidad, mediante la concienciación de los ciudadanos. En este mismo sentido se encuentra el convenio 169 de la Organización Internacional del trabajo (OIT. 2005), cuando considera que se deben 
tomar medidas desde la educación para evitar la discriminación de los pueblos indígenas. “Deberán adoptarse medidas de carácter educativo en todos los sectores de la comunidad nacional, y especialmente en los que estén en contacto más directo con los pueblos interesados, con objeto de eliminar los prejuicios que pudieran tener con respecto a esos pueblo" (OIT; Art. $31)$.

La convención relativa a la lucha contra la discriminación en la esfera de la enseñanza, de 1960 convocada por la UNESCO; concluyo entre otras cuestiones que la educación debe tender al pleno desenvolvimiento de la personalidad humana y a reforzar el respeto de los Derechos Humanos y de las libertades. Debe respetarse la libertad de los padres o, en su caso, de los tutores legales de elegir para sus hijos establecimientos de enseñanza que no sean los mantenidos por los poderes públicos, pero que respeten las normas mínimas que puedan fijar o aprobar las autoridades competentes, dar a sus hijos, según las modalidades de aplicación que determine la legislación de cada Estado, la educación religiosa y moral conforme a sus propias convicciones; en que, además, no debe obligarse a ningún individuo o grupo a recibir una instrucción religiosa incompatible con sus convicciones.

Debe reconocerse a los miembros de las minorías nacionales el derecho a ejercer las actividades profesores que les sean propias de acuerdo a sus tradiciones culturales y ancestrales, por ello tienen derechos a establecer y mantener escuelas, según la política de cada Estado en materia de educación, emplear y enseñar su propio idioma

Se hace evidente la necesidad de reiterar desde la educación el reconocimiento de las minorías y la necesidad de generar políticas tendientes a mostrar la obligatoriedad de promover en las escuelas la ruptura de los estereotipos que llevan a la discriminación por ello en la Declaración sobre la raza y los prejuicios sociales las Naciones Unidas consideran que el Estado, 
todas las autoridades competentes y todo el cuerpo profesor, tienen la responsabilidad de procurar que los recursos en materia de educación de todos los países se utilicen para combatir el racismo, en particular haciendo que los programas y los libros de texto den cabida a nociones científicas y éticas sobre la unidad y la diversidad humanas y estén exentos de distinciones odiosas respecto de algún pueblo; asegurando la formación del profesor para esos fines y poniendo los recursos del sistema escolar a disposición de todos los grupos de población sin restricción ni discriminación alguna de carácter racial, tomando las medidas adecuadas para remediar las restricciones impuestas a determinados grupos raciales o étnicos en lo que respecta al nivel de educación y al nivel de vida con el fin de evitar en particular que sean transmitidas a los niños.

En 1990 la Organización de las Naciones Unidas, saco a la luz pública las directrices para la prevención de la delincuencia juvenil; una serie de recomendaciones que tienden a proponer soluciones para la cada vez más amplia participación de jóvenes en la comisión de delitos que estremecen a la sociedad; una de las medidas que aconseja la ONU tiene que ver con la educación ya que esta debe estar interesada además de la formación académica de los educandos en:

a) Enseñar los valores fundamentales y fomentar el respeto de la identidad propia y de las características culturales del niño, de los valores sociales del país en que vive el niño, de las civilizaciones diferentes de la suya y de los Derechos Humanos y libertades fundamentales; b) Fomentar y desarrollar en todo lo posible la personalidad, las aptitudes y la capacidad mental y física de los jóvenes; c) Lograr que los jóvenes participen activa y eficazmente en el proceso educativo en lugar de ser meros objetos pasivos de dicho proceso; d) Desarrollar actividades que fomenten 
un sentimiento de identidad y pertenencia a la escuela y la comunidad; e) Alentar a los jóvenes a comprender y respetar opiniones y puntos de vista diversos, así como las diferencias culturales y de otra índole; f) Suministrar información y orientación en lo que se refiere a la formación profesional, las oportunidades de empleo y posibilidades de carrera; g) Proporcionar apoyo emocional positivo a los jóvenes y evitar el maltrato psicológico; h) Evitar las medidas disciplinarias severas, en particular los castigos corporales. (ONU.1990. Párr. 20).

Entonces es la educación una alternativa para mitigar en las y los jóvenes conductas que van en contra de los acuerdos sociales, políticos y legales establecidos, generando en ellos y ellas el reconocimiento de sus derechos fundamentales y las alternativas para el disfrute pleno de los mismos y las formas posibles de exigibilidad.

El Derecho Internacional Humanitario (DIH) también ha propuesto acciones para desarrollar en la educación, con el fin de promover el respeto, la práctica y la promoción de los Derechos Humanos y el DIH; entre estas tenemos los cuatro convenios de Ginebra de 1949; los cuales obligan a los Estados a incorporar en la educación la enseñanza del DIH, en los programas de formación de los militares y en lo posible de toda la población. Así mismo los dos protocolos adicionales reiteraron el compromiso de los Estados en el artículo 83 del protocolo I y en el 19 del protocolo II. Para reiterar que la población civil y quienes participan de las guerra y quienes tienen a su cargo la asistencia de las víctimas de la guerra y los conflictos armados tengan el pleno conocimiento y actúen según lo estipulado por el DIH.

La convención contra la tortura y otros tratos o penas crueles, inhumanas o degradantes en su artículo 10 considera que el Estado debe incluir en la educación de los funcionarios civiles 
y militares y todos los que tengan participación en interrogatorios la prohibición de la tortura a quienes se encuentran privados de libertad (ONU.1987.Parr.4)

La Declaración y Programa de Viena de 1993, dedico un apartado a la educación en Derechos Humanos; en ella se considera que la educación en Derechos Humanos permitiría construir relaciones armoniosas entre las comunidades y que se debe incluir en los programas de estudio el Derecho Internacional Humanitario (DIH), los Derechos Humanos y la democracia.

La declaración sobre el derecho y el deber de los individuos, los grupos y las instituciones de promover y proteger los Derechos Humanos y las libertades fundamentales universalmente reconocidos considera que es deber del Estado, promover y facilitar la enseñanza de los Derechos Humanos y las libertades fundamentales en todos los niveles de la educación, y garantizar que los que tienen a su cargo la formación de abogados, funcionarios encargados del cumplimiento de la ley, personal de las fuerzas armadas y funcionarios públicos incluyan en sus programas de formación elementos apropiados para la enseñanza de los Derechos Humanos.

Esta declaración no solo considera al Estado como capacitador, sino que habla de las ONG y los particulares ya que ellos tienen la importante misión de contribuir a sensibilizar al público sobre las cuestiones relativas a todos los Derechos Humanos y las libertades fundamentales mediante actividades de enseñanza, capacitación e investigación en esas esferas, teniendo en cuenta las diferentes mentalidades de las sociedades y comunidades en las que se llevan a cabo sus actividades.

En cuanto a las normas y leyes nacionales de las cuales se desprenden obligaciones al Estado y a los particulares para la educación en y para los Derechos Humanos se tiene como primera medida la Constitución Política del país en la cual se consagro el principio de Bloque de 
Constitucionalidad, que quiere decir que hacen parte del ordenamiento Jurídico Interno todos los acuerdos que en materia de Derechos Humanos se creen a nivel internacional; además la Constitución consagra la educación como un derecho fundamental cuando dice:

La educación es un derecho de la persona y un servicio público que tiene una función social; con ella se busca el acceso al conocimiento, a la ciencia, a la técnica, y a los demás bienes y valores de la cultura. La educación formará al colombiano en el respeto a los Derechos Humanos, a la paz y a la democracia; y en la práctica del trabajo y la recreación, para el mejoramiento cultural, científico, tecnológico y para la protección del ambiente (Const.1991.Art.67).

En esta vía, es posible considerar que la carta constitucional de Colombia, considera la educación como un derecho de los ciudadanos y que el Estado debe garantizarlo entre los cinco y los quince años. Desde la expedición de la Ley General de Educación (Ley 115, 1994) que establece la educación como un proceso permanente, personal y social, que se fundamenta en la concepción integral de la persona, su dignidad y sus derechos y deberes, comenzó a desarrollarse el derecho que le asiste a todos los colombianos de tener una educación gratuita y prestada por el Estado.

Los fines de la educación establecidos en esta Ley se alinean, con lo expuesto hasta aquí ya que en su artículo 5, promueven el pleno desarrollo de la personalidad dentro del marco jurídico que nos rige, la formación integral y en el respeto a la vida, a los Derechos Humanos, la promoción de la paz, los principios democráticos, pluralismo, justicia, solidaridad y equidad, así como en el ejercicio de la tolerancia y de la libertad. 
De esta manera las leyes comenzaron a garantizar el derecho a la educación que las niñas, niños y jóvenes de Colombia tienen, sin embargo la discusión de fondo era sobre si garantizar el derecho era simplemente abrir más cupos en los planteles educativos o qué otros componentes deberían asociarse, con el fin de hablar del cumplimiento de los acuerdos internacionales en materia de educación y educación en Derechos Humanos de los Estados. En el caso Colombiano desde distintos frentes los profesores y organizaciones sociales exigieron del Estado una política mucho más integral con el fin de hacer realidad el derecho a la educación para los menores en todo el territorio nacional.

El decreto 1860 de 1994, que reglamento la Ley General de Educación y que en su artículo 36 desarrolla la intensión de trabajar en diversos escenarios como la educación en Derechos Humanos y en prácticas como el cuidado del medio ambiente o la educación sexual, que en términos generales tienen que ver con la práctica del respeto y promoción de una cultura de los Derechos Humanos en el país, hacen parte de los mecanismos implementados para hacer realidad el ejercicio de la formación para y en Derechos Humanos.

Como otra alternativa tenemos el Código de Infancia y Adolescencia (Ley 1098 del 2006); que intenta de una manera integral promover ambientes ideales para que los niños, niñas y los adolescentes crezcan felices en el seno de las familias y la sociedad. Este instrumento es importante a la hora de entender como debe ser la relación de los jóvenes con la justicia y como se deben edificar políticas que los beneficien tanto a nivel de la educación como en otras instancias de la participación de los jóvenes en la vida nacional.

Con la expedición de la Ley 1732 de 2014, se establece como obligatoria la Catedra de la Paz en todas las instituciones educativas del país, en el nivel de preescolar básica y media. De acuerdo a la misma ley pretende convertirse en un "espacio para el aprendizaje, la reflexión y el 
diálogo sobre la cultura de la paz y el desarrollo sostenible que contribuya al bienestar general y el mejoramiento de la calidad de vida de la población”. El decreto reglamentario de dicha ley (1038 de 2015) entre otras cosas amplia las intenciones del Estado, al considerar que las instituciones deben desarrollar por lo menos dos de las temáticas que este propone; en términos generales esta ley reconoce implícitamente que el problema de los Derechos Humanos no tiene que ver fundamentalmente con su exigibilidad o con la falta de conocimientos de la población sobre su existencia; más bien considera que es el desarrollo de una cultura de paz, la que conseguirá un cambio en lo que tienen que ver con los Derechos Humanos en Colombia y ubica en las escuelas una enorme esperanza de poder consolidar mediante una educación en Derechos Humanos, una forma diferente de dirimir los conflictos y de relacionarse unos a otros.

Existe una tensión permanente entre los acuerdos internacionales y lo que podríamos llamar la realidad; que tiene que ver con que a pesar que Colombia ha firmado los diversos acuerdos y pactos internacionales y que la Constitución obliga y equipara el derecho internacional de los Derechos Humanos a las leyes nacionales mediante el bloque de constitucionalidad, el escenario frente a la violación y vulneración de los Derechos Humanos no mejora, debido a múltiples razones entre las cuales podríamos considerar algunas de la siguiente manera; el conflicto armado colombiano obnubila los esfuerzos por comprender otros espacios en los cuales se violan permanentemente los Derechos Humanos de los ciudadanos; son ejemplos de ello la crisis de la salud, la falta de garantías sindicales, la educación pública, la situación de las minorías (étnicas y sexuales por mencionar solo dos) la insuficiente infraestructura para integrar a las personas en condición de discapacidad, los servicios para mejorar la vida de los adultos mayores y muchas más, que nos permitirían concluir que es permanente esta tensión entre lo que se legisla internacional e internamente y la vida real por decirlo de alguna manera. 
Por otro lado hay una tensión entre quienes consideran que los Derechos Humanos son compromisos más profundos que leyes y acuerdos y tienen que ver con responsabilidades éticos y morales de los seres humanos entre ellos y del Estado para con ellos, esta inquietud está presente por ejemplo en la creación de la catedra dela paz que se plantea como asignatura obligatoria, sin tener en cuenta que los esfuerzos deben dirigirse a democratizar la vida diaria de las comunidades y no solo a crear un espacio de clase nuevo que podría convertirse en una carga para los educandos.

Finalmente hay una tensión derivada de los compromisos que como Estado adquiere Colombia y que deben ser desarrollados por los agentes del Estado en sus diversos escenarios de trabajo; nos referimos primordial mente a los profesores del servicio público de educación que son los que tiene la obligación por ser servidores públicos de conocer y difundir por un lado las leyes y acuerdos que adquiere el país al firmar los pactos y tratados y de desplegar las estrategias que permitan crear unas comunidades de respeto y practica de los Derechos Humanos en la escuela pero en la sociedad; consideramos que hacer visibles los discursos que han elaborado los profesores frente a la EDH, contribuirá a zanjar o al menos a amortiguar la tensión que en este caso existe.

\subsection{Estado del arte.}

La temática de la Educación en Derechos Humanos (EDH) ha sido ampliamente trabajada, por diversos investigadores y a propósito de muy disimiles proyectos; en este sentido podemos dar cuenta de distintas líneas de trabajos como son; las pedagogías asociadas a la educación en Derechos Humanos, en las que se destacan entre las más influyentes a nivel latinoamericano los aportes de la pedagogía crítica, los enfoques humanistas y la pedagogía de la alteridad; otra línea de investigación tiene que ver con las didácticas en tanto técnicas de trabajo en el aula y 
materiales de consulta, en este sentido la UNICEF, los ministerios y secretarias de educación y organizaciones privadas han desarrollado materiales de diversa naturaleza tanto para los profesores como para trabajo con estudiantes en el aula, juegos de roles, lecturas críticas de la realidad y muchos más (UNICEF va a la escuela, Cuadernos de enseñanza de los Derechos Humanos de la UNESCO y Escuela y desplazamiento del MEN; entre otros) cuyo común denominador podría ser la construcción de herramientas que permitan entender, analizar y transformar la realidad circundante.

Otro nicho de trabajo tiene que ver con el análisis y sistematización de las experiencias que han puesto en marcha actores diversos como la escuela, las organizaciones de la sociedad civil, organizaciones no gubernamentales, tanto a nivel formal como no formal o informal; también se han hecho trabajos biográficos sobre educadores en Derechos Humanos, en los que se destaca la manera en la cual accedieron al trabajo en Derechos Humanos, las experiencias que han tenido con diversos actores del proceso educativo, los recursos que utilizan en sus prácticas pedagógicas y cuales han sido los obstáculos más frecuentes con que se han estrellado y como los han dejado atrás. Aún así son pocas las experiencias de trabajos investigativos que busque dar cuenta de los discursos elaborados por los profesores sobre la EDH, sobre la perspectivas con las cuales lleva este discurso a las aulas de clase, sobre las fuentes filosóficas, jurídicas e históricas que utilizan los profesores a la hora de hilar su discurso y de llevarlo hasta sus educandos.

Desde el año 2002, el Instituto Interamericano de Derechos Humanos (IIDH en adelante) una entidad privada que tiene estrechos vínculos con la Comisión Interamericana de Derechos Humanos (CIDH) viene elaborando un "Informe Interamericano de la Educación en Derechos Humanos" en el cual se considera como propósitos fundamental terminar con todas las formas de discriminación y exclusión social; con el fin de conseguir su tarea principal y ve en la Educación 
en Derechos Humanos (EDH) la herramienta fundamental, que debe desarrollar el sistema interamericano y los gobiernos democráticos de la región para conseguir esa meta. En el mencionado informe participan 19 países de la zona y en él se hace una comparación entre finales del siglo XX y comienzos del XXI.

El primer informe estuvo dedicado al desarrollo de la normativa que existe a nivel internacional sobre la Educación en Derechos Humanos (EDH) y la manera en la cual los Estados miembros del sistema interamericano la han ido incorporando en su ordenamiento jurídico interno, mediante la expedición de leyes generales de educación que contemplen la EDH como elemento fundamental, la manera en la cual se ve reflejada esa preocupación en las políticas públicas y como se ha desarrollado el contenido de la EDH, en las instituciones del Estado. En este sentido el objetivo del primer informe fue "el dominio temático del marco legal que establece y caracteriza a la educación en Derechos Humanos dentro de la normativa interna de los países estudiados durante la última década e interpreta en qué medida tales tendencias constituyen un progreso o no" (IIDH, 2002, p.3).

De otro lado en el primer informe se caracteriza y define la educación en Derechos Humanos en el ámbito del sistema interamericano como “...un proceso de adquisición de determinados conocimientos, habilidades y valores necesarios para conocer, comprender, afirmar y reivindicar los propios derechos sobre la base de las normas dispuestas en los distintos instrumentos internacionales en conexión con la normativa interna" (IIDH, 2002.p.4) y se concluye que los países de la región están haciendo un importante esfuerzo, con el fin de posicionar el tema de la $\mathrm{EDH}$, al interior de sus países, pero que hace falta efectuar reformas que tengan en cuenta el tema y desarrollarlas de una manera más acelerada. 
En el año 2003 se realizó el segundo informe; el cual se dedicó a analizar el derecho a la Educación en Derechos Humanos, desde su incorporación al currículo y los textos escolares; el objetivo de éste fue mostrar la manera en la que se ha incorporado el contenido de la EDH "en los instrumentos legales, administrativos, pedagógicos y didácticos que orientan y realizan la educación en la práctica cotidiana..." (IIDH, 2003, p.9). Consideran los autores que es común que se piense como educación en Derechos Humanos a la capacitación en los mismo, cuando esta apenas es una parte del proceso, por ello respaldaran la idea que "la educación en Derechos Humanos es más bien un eje transversal del derecho a la educación que debería estar presente en lo sustantivo y metodológico y en todas las formas posibles de enseñanza formal e informal" (IIDH, 2003, p.12).

Es decir que la educación en Derechos Humanos estaría imbuida en todo el proceso de enseñanza-aprendizaje; desde la confección de la sesión de clase, pasando por los materiales, el contexto y hasta llegar al ejercicio experiencial del aula; puesto que el profesor siempre pensara en clave de Derechos Humanos, sin importan la sesión que deba impartir.

Se concluye de este informe que para el 2003, existían contenidos intencionados sobre Derechos Humanos en asignaturas en todos los países examinados lo cual muestra una tendencia cada vez más consolidada hacia la formalización al interior del currículo de la EDH.

Consideran alentador el estado en el que se encontraba la EDH, en los países que hicieron parte de la investigación, puesto que se han tomado medidas progresivas en lo que tiene que ver con las legislaciones, la adaptación de las instituciones del estado y desde el ámbito pedagógico; para un progresivo desarrollo del tema; sin embargo estas son desiguales en la región lo cual indicaría que hay que continuar haciendo esfuerzos para que los Estados actualicen en sus territorios las prácticas de la educación en Derechos Humanos en las escuelas. 
En el año 2004, el IIDH, produjo el tercer informe sobre EDH en la región, este fue dedicado a analizar dos asuntos fundamentales a la hora de propiciar cambios en la educación en Derechos Humanos; por un lado las políticas públicas sobre la formación profesional de los futuros profesores y de otra parte los planes de actualización para aquellos profesionales de la educación que prestan sus servicios en los sistemas educativos nacionales. Considera El Instituto Interamericano de Derechos Humanos (2004), que uno de los medios fundamentales a la hora de incorporar la EDH en los sistemas formales debe ser "la correspondiente formación y entrenamiento continuo de los profesores que trabajan en los establecimientos educativos del sistema escolar...” (p.8).

En lo que tiene que ver con la formación de los profesores se considera que existen dos claras tendencias; por una parte entre los educadores del ciclo básico "predomina una concepción generalista, que asocia la formación con principios pedagógicos generales y con los contenidos del currículo escolar que debe transmitir" mientras que en aquellos profesores que prestan su servicio en la educación media "predomina una concepción especializada, centrada en el dominio de una disciplina específica pero con una formación pedagógica débil y disociada.” (IIDH, 2004, p.9) lo cual hace que el panorama no sea del todo alentador para la implementación de la EDH; pues para ello es imprescindible tener mayor fortaleza en los aspectos pedagógicos.

Las escuelas Normales Superiores y las Facultades de educación son las encargadas de educar en la mayor parte de la región a los futuros educadores ya que se presenta un fenómeno que es el alejamiento gradual de los Ministerios de Educación o las Secretarias, de esa responsabilidad que le corresponde, por ello no existen criterios claros frente a su preparación y en las leyes no se toma esta como criterio de ascenso en el escalafón o aumento salarial. 
En lo que hace referencia a la manera de actualización de los profesores en ejercicio; consideran que en América Latina

Ha sido y es la oferta directa de cursos, jornadas u otras actividades de capacitación de duración variada - seminarios, congresos, talleres, etc. -, que por lo general se planifican anualmente en consonancia con los lineamientos macro-educativos vigentes y que abordan tanto aspectos curriculares como metodológicos y de gestión institucional (IIDH, 2004, p.10).

El informe concluye considerando que a pesar de los esfuerzos que los países de la región han hecho para crear normas que tiendan a la formación de los educadores para la EDH, esta es aún una tarea inconclusa y que son muchos los esfuerzos que hacen falta ya que en muchos casos no existe normativa sobre la cuestión y en otros esta es ambigua.

En diciembre del 2005, salió el cuarto Informe Interamericano sobre la EDH, el cual se dedicó fundamentalmente a realizar un análisis sobre

El progreso que han alcanzado los países de la región en el establecimiento de la EDH, como una política de Estado para conseguir el objetivo propuesto el IIDH, le dio prioridad a mostrar las acciones que se han realizado por parte del Estado y otros actores con el fin de crear los Planes Nacionales de EDH o instrumentos equivalentes que presupongan la toma de decisiones políticas, técnicas y económicas de largo plazo y sostenibilidad (IIDH, 2005, p.6).

Consideran los autores que con esas pruebas se puede medir hasta qué punto existe una verdadera política pública para favorecer la inclusión de la EDH, en los diferentes espacios de la vida pública y privada de los ciudadanos y en general del país. 
Concluye el documento que se han hecho esfuerzos para consolidar una política pública en EDH en la región, los cuales se ven reflejados en la adopción de Planes Nacionales de Educación en Derechos Humanos (PLANEDH en adelante) o sus equivalentes, pero estos son muy recientes y no fue posible dar cuenta de sus resultados, la mayor debilidad está en la escasa planeación financiera a mediano y largo plazo y esta se concentra en planificación de acciones puntuales.

En lo que tiene que ver con el contenido profundo de los planes; se puede concluir que en ellos se refleja una concepción universal, integral e interdependiente de todos los Derechos Humanos y a la vez una carencia en el acceso a los derechos que está íntimamente relacionada con las desigualdades; en especial en lo que se refiere a la pobreza como expresión de la desigualdad económica, la exclusión como expresión de la desigualdad política y la discriminación como enunciado de la desigualdad social y cultural. Lo cual se constituye en sí mismo en un reto para los PLANEDH, ya que estas pueden traducirse en líneas de acción de los mencionados planes.

El quinto informe se dio a conocer en diciembre del 2006, este fue dedicado especialmente a

diseñar una propuesta curricular y metodológica que ayude a cumplir con los fines que establece el artículo 13 y 13.2 del Protocolo de San Salvador...Es urgente en consecuencia completar la inserción de los Derechos Humanos en los programas nacionales y especialmente en el rango escolar de la edad comprendida entre los 10 y 14 años (IIDH, 2006, p.7).

En este informe se hace hincapié en dos cuestiones que consideran los investigadores como fundamentales; con miras a incorporar, mejorar y ampliarla educación en y para los 
Derechos Humanos en la región. La primera tiene que ver con la elección de los contenidos que deben hacer parte del currículo y la segunda hace referencia a los espacios adecuados para poder desarrollar los contenidos.

Para los investigadores del IIDH, la escuela es vista como un ente vivo que posee en su interior las contradicciones inherentes a la sociedad, así mismo la entienden como un campo de batalla en el cual se trasmiten de manera explícita o implícita y de forma consciente o inconsciente valores, actitudes, modelos y conductas que le permiten a los seres humanos transformar o no la vida.

Se proponen diversas opciones a la hora de concebir los contenidos que deberían desarrollarse o privilegiarse en las aulas; pero manteniendo siempre el principio de integralidad característico de los Derechos Humanos. Así mismo se analizan las maneras en las que se pude insertar la EDH en el currículo y en este sentido se concluye; que se puede trabajar de manera transversal tocando todas las áreas y asignaturas o desde una mirada específica y disciplinar en la que se desarrollarían los contenidos desde un espacio de clase y de asignatura.

El sexto informe se presentó en el año 2007 y es considerado como el primero de una segunda etapa de medición; en este se retoman las temáticas ya analizadas, pero se tiene de fondo la participación democrática de los estudiantes en la gestión educativa.

Lo fundamental en este informe será analizar el desarrollo de normatividad que permita la participación de los educandos en el gobierno estudiantil; para tal fin se propusieron una serie de indicadores con los cuales se podría medir la voluntad estatal convertida en políticas públicas frente a la participación de los jóvenes en la escuela 
(i) la existencia de dependencia en el ministerio de educación -a nivel macro (nacional o provincial) - que esté a cargo de ejecutar y desarrollar un programa de gobierno estudiantil;

(ii) la identificación de normas, instrucciones, pautas o lineamientos expresos que definen quiénes son los responsables de poner en práctica las estrategias y actividades concretas del programa de gobierno estudiantil en el nivel micro (de las instituciones educativas), y (iii) si el ministerio de educación tiene previstos recursos específicos para la implementación del gobierno estudiantil en las escuelas y, en este caso, qué porcentaje representa del presupuesto general del ministerio y cuáles son los rubros que cubre ese presupuesto." (IIDH, 2007, p.31).

Consideran los autores del informe que la existencia de un programa dirigido por el Estado con el fin que las niñas, niños y jóvenes puedan participar democráticamente en los asuntos de la escuela, daría cuenta de la voluntad política para desarrollar la EDH, entonces "la existencia de un programa de gobierno estudiantil es un indicio relevante de la voluntad política de un Estado de educar a sus niños, niñas y adolescentes en sus derechos, en las instituciones y mecanismos de la democracia" (IIDH, 200, p. 35)

El IIDH 2007; busca en este Informe “(i) en reconocer explícitamente dentro de su marco normativo alguna forma de organización estudiantil y (ii) en proveer los medios institucionales clave para hacerla realidad en los centros educativos.” (p.38). Las conclusiones de este trabajo son positivas en lo que tiene que ver con el espacio que han ganado los niños, niñas y jóvenes en el escenario escolar y como su participación activa en la escuela es cada vez mayor en la manera de comprender la escuela como escenario de educación en democracia y valores por un lado y en reconocimiento de sus Derechos Humanos y en participación política por otro. 
La ampliación de la participación de los jóvenes en los gobiernos estudiantiles, se ha dado en uno de tres escenarios; mayor participación explicita en el escenario estudiantil, organizaciones cada vez más consolidadas y por lo mismo más participativas y con mayor peso o ampliación del proceso decisorio por parte de las organizaciones tipo gobierno estudiantil al interior de los planteles educativos.

A finales del año 2008, se dio a conocer el séptimo Informe Interamericano de la Educación en Derechos Humanos, este trabajo que lleva por título: Desarrollo de conocimientos específicos de Derechos Humanos en los programas de estudio: 10 a 14 años, concentro sus esfuerzos en reconocer las asignaturas y los programas que se están llevando a cabo en el tema de la $\mathrm{EDH}$, analizar los alcances y la forma de elaboración de los programas, cuales son los conocimientos específicos que aprenden los niños sobre el tema en cuestión, cuales son los conceptos y su desarrollo por parte de los educandos, de qué manera se incorpora la historia de los Derechos Humanos y si se tienen en cuenta las instituciones encargadas de velar por el cumplimiento de los Derechos Humanos a nivel interno y las internacionales.

La lógica con la que está hecho este informe mantiene los campos temáticos que se abrieron desde los primeros informes y fija su mirada en el segundo de ellos, centrándose en los Currículos Escolares con el fin de entender cuál ha sido su desarrollo en los últimos años; pero va más allá al examen del currículo el subtema del gobierno estudiantil iniciado con el VI Informe (2006), construyéndolo como un indicador que "permite identificar si esta experiencia de organización y participación del estudiantado se aborda también como un conocimiento explícito dentro de los programas de estudio, asociado al ejercicio y aprendizaje de los Derechos Humanos" (IIDH, 2008, p.31). 
Con lo cual se complejiza mucho la presentación de los resultados obtenidos, pero al mismo tiempo se enriquece la experiencia no solo de los investigadores, si no a la vez de los educandos. Se plantea que el desarrollo de la EDH, debe partir de un enfoque holístico, que permita comprenden al ser humanos desde sus múltiples dimensiones y que en general toda practica de educación de este tipo debería incluir al menos tres tipos de contenidos

1. Información y conocimientos sobre Derechos Humanos y democracia. 2. Valores que sustentan a los principios y la normativa de los Derechos Humanos y la democracia, y actitudes coherentes con esos valores (o predisposiciones, como las llama la literatura de EDH en inglés). 3. Destrezas o capacidades para poner en práctica con eficacia los principios de Derechos Humanos y democracia en la vida diaria. (IIDH, 2008, p. 33).

Las variables utilizadas en el estudio tienen que ver con; conceptos y desarrollos conceptuales, la historia y las normas e instituciones las cuales son esenciales a la hora de comprender la naturaleza, los orígenes y el sentido que tienen los Derechos Humanos como propuesta de cambio para las sociedades actuales.

El estudio concluye que son muchos los avances que la región ha conseguido en lo que tiene que ver con poner en marcha el Protocolo de San Salvador en lo que tiene que ver con la $\mathrm{EDH}$, aunque siguen existiendo vacíos que deben solucionarse sobre todo en lo que tiene que ver con la cantidad, calidad y coherencia interna que tienen los contenidos específicos en Derechos Humanos en el currículo, principalmente en los estudios sociales, ética y valores, pero con miras a extenderse a todos los conocimientos que se imparten en las instituciones escolares.

El noveno informe del IIDH, se presentó en el año 2010, que tiene como finalidad; “ofrecer un panorama actualizado sobre los desarrollos metodológicos de la educación en 
Derechos Humanos en los libros escolares" (p.31), este documento tiene como marco de referencia los esfuerzos que se hicieron con el fin de hacer realidad el Pacto Interamericano por la Educación en Derechos Humanos (PIEDH) que fue producto de mucho trabajo y esfuerzo y que se concretó en Lima en el 2010. El noveno informe considera como punto focal los textos escolares, tal y como ya se había hecho en el octavo informe, pero como novedad "este centró su mirada en dos nuevas dimensiones de los contenidos: los valores y actitudes de Derechos Humanos, y las destrezas o capacidades para actuar por los Derechos Humanos” (p. 9)

En este informe dela IIDH (2010), se hace un análisis de la importancia de la metodología a la hora de realizar el proceso de enseñanza y en constancia considera "que el progreso de la EDH depende también de que esos contenidos curriculares se enseñen utilizando una metodología aceptable, es decir, acorde con y respetuosa de los principios de Derechos Humanos" (p. 33). El principal criterio que se utilizó para elegir del universo de textos escolares fue el de explicitud, que significa que se dio prioridad a aquellos en los cuales la referencia a los Derechos Humanos fuera explicita y directa.

El informe concluye que es muy positivo el desarrollo de los textos escolares en los que se incluyen ejercicios sobre Derechos Humanos y que estos tienen la doble función de servir tanto a los educandos, como a los profesores. Los textos son muy variados en la región y se han ido actualizando teniendo en cuenta la mirada de los Derechos Humanos.

Para el 2011, salió el décimo informe Interamericano de Educación en Derechos Humano, que verso sobre, El desarrollo de las políticas de convivencia y seguridad escolar con enfoque de derechos, este trabajo se enmarca en un contexto de alta inseguridad y desaliento de las comunidades en América Latina producido por la alta criminalidad y la violencia que ingresa 
a las aulas de clase; es por ello que este pretende indagar sobre los avances, progresos y carencias de las políticas públicas para prevenir la violencia en el ámbito escolar.

El punto nodal del presente informe es diagnosticar como intervienen los Estados, ante la creciente y preocupante violencia en el ámbito de la escuela, así mismo se pretende dar cuenta de las prácticas que podrían ser implementadas para contrarrestar y prevenir la violencia que se cierne sobre los espacios educativos.

Este informe de la IIDH (2011), "ha permitido concluir que la exclusión y la desigualdad son graves problemas que deben abordarse desde los Derechos Humanos y que se debe analizar la brecha social como un fenómeno que atenta contra el derecho a la educación sin violencias". (p.11). Un entorno violento no permite que los educandos puedan disfrutar del derecho a una educación que les permita salir de la exclusión y considerarse incluidos en los proyectos de nación y en la sociedad.

De esta manera se ha dado cuenta de los diversos informes que sobre la Educación en Derechos Humanos han producido al interior de uno de los organismos más influyentes en este aspecto en toda la región; son mucho los temas que ellos han tratado y todos revisten importancia capital a la hora de poner en marca las políticas públicas que garanticen no solo el derecho a la educación, sino a una, que se construya desde el disfrute de los Derechos Humanos. Aun así, el Instituto Interamericano de Derechos Humanos (IIDH) no ha dedicado un estudio a analizar cuáles son los discursos que han desarrollado los profesores frente a la Educación de los Derechos Humanos.

Tünnermann Bernheim (1999) escribió un artículo denominado Educación en Derechos Humanos en los sistemas educativos en el que el autor, analiza la EDH en los sistemas 
educativos, mediante una reflexión sobre los lazos que unen a los valores, los principios éticos y los Derechos Humanos allí considera el autor que estos últimos "representan el mejor repertorio de valores universales en la sociedad contemporánea” (p. 1).

Luego se discute la posibilidad de educar en valores desde diversas perspectivas teóricas concluyendo, que una educación integral y de calidad necesariamente debe centrar sus esfuerzos en una enseñanza en valores y que no es posible sacarle el cuerpo a este tema en la educación.

Finalmente hace una revisión de las recomendaciones de los órganos internacionales sobre la $\mathrm{EDH}$, en todos los niveles del sistema educativo. Hace el escritor una extensa defensa de como se ha visto en problema de los valores en la filosofía occidental y muestra la manera en la que se ha edificado el discurso de los Derechos Humanos; finalmente hace un recorrido por los aportes que se han hecho desde diversas instituciones para la EDH, en diversos niveles y escenarios educativos.

En 1994, el Instituto Interamericano de Derechos Humanos (IIDH) saco a la luz un texto auto formativo, para los profesores interesados en introducirse de lleno a trabajar en la EDH que lleva por título; Educación en Derechos Humanos: texto auto formativo este fue un esfuerzo didáctico del Instituto, debido principalmente a que en muchos lugares de América los profesores están interesados en trabajar en el tema pero no saben cómo empezar, no entienden hacia donde se debe dar el primer paso en este arduo camino.

El texto es un esfuerzo didáctico que propone ejercicios de reflexión para la enseñanza de los Derechos Humanos al interior de la escuela, considera que no es posible enseñar este tema desde los lugares comunes de la didáctica si se quiere tradicional, que quien se introduzca en este camino debe sentir incomodidad, para que nunca se quede quieta la mente y produzca sus ideas y 
materiales propios y en contexto; puesto que la $\mathrm{EDH}$, no puede entenderse desde recetas cual galera de mago.

Los expertos en el tema de la EDH, han dejado de lado el tema de la didáctica, por razones comprensibles, como que no se pude convertir en un discurso más que ingresa a la escuela, pero que no cambia nada, aun así es necesario dar orientaciones a aquellos que sinceramente quieren trabajar en el aula de clase y no saben o no han descubierto su particular camino; es así como el esfuerzo de este texto tiene sentido en la Educación en Derechos Humanos, en la región Latinoamericana.

En el 2007, fue publicado el artículo La Practica Educativa de Derechos Humanos en la Educación Primaria de la profesora Alma Delia Torquemada González, en el cual se reflexiona sobre la $\mathrm{EDH}$, en tiempos que para nada son de respeto, tolerancia, camaradería ni mucho menos paz; en estos momento convulsionados hablar del tema puede parecer un contra sentido, pero es en ellos en los que más se hace necesario hacerlo.

En tiempos en los que los medios de comunicación le presentan competencia a la escuela como escenario natural de aprendizaje de los valores fundamentales que busca desarrollar la sociedad; esta se convierte en una tarea fundamental "una de las tareas que debe encomendarse a la escuela como institución educativa no es únicamente transmitir conocimientos, habilidades y métodos, sino poner cada vez mayor énfasis en la formación de los valores básicos de la sociedad.” (Torquemada González, 2007, p.182) ya que estos dan sentido a la dignidad humana y propician la capacidad de crear y re-crear proyectos de vida viables para los educandos, considerando que ese es el mandato filosófico que debe hacer la escuela y puede ser hoy la única razón para mantenerla como institución fundamental de la sociedad. 
Considera Torquemada (2007), que la fuerza de la EDH, radica en que esta no puede ser considerado como un mero saber que está fuera del ser humano, sino que por el contrario lo obliga a tomar una posición, a tomar partido y a sentar posición frente a lo que sucede en la sociedad ya que este conocimiento se crea y recrea constantemente. Vincular la EDH, en el ámbito formal, lleva implícito un reto que se refiere a si estos deben ingresar en el currículo de manera trasversal y por lo tanto alimentar los diversos conocimientos que se desarrollan en la escuela; si se le debe dar un espacio y unos tiempos específicos y de allí considerarlos como una asignatura más que deben cursar y aprobar los educandos o si por el contrario se debe tratar como una finalidad de la educación y por lo tanto estar explícitamente en la filosofía institucional, en el plan de estudios y en las distintas instancias al interior de las instituciones; este debate actual y sin resolver alimenta el objeto de estudio de este trabajo.

Existen propuestas que plantean que el trabajo de la educación en Derechos Humanos debe partir de la realidad de las violaciones a los Derechos Humanos; con el fin de generar perspectivas claras de restitución de los derechos de las comunidades que han sido víctimas; tal es el caso del trabajo que lleva a cabo la Universidad Católica del Oriente de Antioquia con las comunidades que han sufrido de desplazamiento en esta región del país. Este grupo de investigación considera temáticas específicas como son el desplazamiento y la memoria histórica de las víctimas, como ejes trasversales para la labor educativa y su aporte a la EDH, radica en que se toman casos reales y en contexto, como punto de partida para una amplia comprensión de los educandos.

La facultad de Ciencias Sociales de la Universidad Jorge Tadeo Lozano, Produjo un documento denominado; Identidades, enfoque diferencial y construcción de paz, en el cual se propone como metodología el trabajo de temas específicos como el enfoque diferencial visto 
como garantía de cumplimiento de derechos para grupos vulnerables en este caso la población indígena, las minorías sexuales, la desterritorialización de ciertas poblaciones y en fin una serie de apuestas por darle cabida a diversos actores en las apuestas pedagógicas frente a la EDH, con una mirada desde las minorías o las poblaciones que por sus condiciones de permanente vulnerabilidad deben tener doble refuerzo desde los Derechos Humanos.

En la revista DEHUIDELA de la facultad de Filosofía y letras del a Universidad Nacional de Costa Rica; dedicada a temas de Derechos Humanos, escribió la profesora Rosa María Mujica un artículo titulado: ¿Qué es educar en Derechos Humanos?, en el cual la autora reflexiona inicialmente sobre el proceso histórico en el cual se configuraron un discurso y unas prácticas sobre los Derechos Humanos y en el cual rescata la noción de Dignidad como el punto fundamental a la hora de comprender los Derechos Humanos. En seguida la profesora Mujica (2000), considera la definición de los Derechos Humanos, en la cual la relevancia es “que estos son necesidades humanas para vivir dignamente y que deben ser satisfechas tanto material como espiritualmente; empero que también son principios, exigencias éticas y cívicas que se traducen en normas legales indispensables para la vida en sociedad" (p. 23).

En seguida el autor se plante las dificultades propias de un ejercicio de educación en Derechos Humanos, entendiendo a este como "Educar en Derechos Humanos no puede reducirse al orden intelectual, pertenece al reino de los sentimientos, de las pasiones, porque supone trascender la palabra y pasar a la acción. Es el desafío de ser más humanos. Educar sería en este sentido el intento de transmitir y adquirir actitudes que encarnan la utopía de los Derechos Humanos." (p.23).

Considera que esta educación posee intrínsecamente una serie de características que el profesor debe potenciar en el trabajo con sus estudiantes; la educación en Derechos Humanos 
debe estar centrada en las personas, más allá de la importancia de las didácticas y los contenidos científicos; es una propuesta en la que el ser humano se debe colocar en el centro y es desde sus conocimientos, sus vivencias y sus necesidades desde donde se debe partir. El aprendizaje debe ser significativo, ya que se debe partir de la capacidad humana para adquirir conocimientos que sean relevantes a las personas y se las debe considerar desde su autonomía como productoras y reproductoras de conocimientos. Todo aprendizaje en este sentido debe ser integrados, en el sentido que comprometa no solo la parte intelectual de los seres humanos, sino sus emociones, si sentido de la ética y la responsabilidad social que cada uno tenemos.

Al reflexionar el papel de los profesores en la educación en Derechos Humanos la profesora Mujica (2000), considera que el compromiso que se adquiere debe hacer que el maestro asuma los valores de los Derechos Humanos como su bandera; pero además un nuevo estilo y una forma diferentes a la hora de ejercer su labor, propone un reencuentro con el otro como un igual; que la escuela debe dejar atrás lo que ella denomina la trampa del logos que consiste en considerar los conocimientos intelectuales como los únicos o al menos como los más importantes y esto es cambiar de horizonte, así se podría dar el salto a una educación en Derechos Humanos en la cual los otros y sus realidades, historias y anhelos puedan florecer y ser y de esta manera construir una cultura de respeto y practica de los Derechos Humanos en nuestra sociedad.

Existen diferentes, trabajos que exploran el papel de la educación en un determinado tema del ámbito de los Derechos Humanos como podría ser la educación para la convivencia, la educación inclusiva o inclusión educativa, la educación para la democracia y la práctica de los valores, la educación ética y la educación moral, la educación constitucional y en mecanismos de participación democráticos. Estos diversos intentos de trabajar un tema específico en el ámbito 
de la educación en Derechos Humanos, han sido enriquecidos con experiencias de aula y se consideran como caminos que se pueden tomar a la hora de trabajar temáticas específicas. Sin embargo, no asumen en su totalidad la educación en Derechos Humanos que como hemos visto debe ser holística y abarcar los diversos aspectos de la misma tratando de no fragmentar los posibles conocimientos que propicie.

De otra parte la Organización de las Naciones Unidas, ha desarrollado un innumerable caudal de trabajos sobre pedagogía y Derechos Humanos, ha contribuido con el desarrollo de materiales didácticos dedicados a cómo enseñar Derechos Humanos en diversos ambientes incluida la escuela y los diversos escenarios educativos, ha asistido con trabajos de especialistas brindando capacitaciones y procesos de mejoramiento de personal profesor; ha contribuido con recursos económicos en la elaboración y puesta en marcha de innovaciones educativas en el ámbito de los Derechos Humanos en la educación y en fin existe una enorme y rica bibliografía frente a la Educación en Derechos Humanos que se ha aprovechado en diversos espacios y apropósito de muchas innovaciones.

Hemos visto como desde el derecho internacional de los Derechos Humanos se le ha dado un mandato a los miembros de la comunidad internacional, para que se desarrolle la educación en Derechos Humanos, en cada una de las naciones miembros de la ONU y por extensión en el mundo entero ya que mediante la presión internacional se puede hacer que países no miembros de las Naciones Unidas respondan ante estas. En este mismo sentido hemos dado cuenta de cómo está inmerso en el ordenamiento jurídico colombiano este tema y de qué manera desde la expedición de la ley general de educación se le ha dado fuerza al tema en la educación formal; aunque sin desconocer que este llego a nuestro país, por la inquietud y el interés de las 
organizaciones de la sociedad civil y desde los espacios no formales e informales de la educación.

Hablamos de los desarrollos conceptuales desde la pedagogía crítica y activa con el fin de hacer de la EDH, un campo de saber practico, en el cual se tengan en cuenta las realidades sociales por las que pasa y viven los estudiantes y en general las comunidades educativas, hemos visto como los presupuestos de la pedagogía de la libertad considera que lo fundamental en este discurso debe ser, la transformación social, es decir comprender la EDH como una herramienta para transformar la realidad de nuestros estudiantes y hacer cumplir o exigir al Estado que haga realidad los Derechos Humanos. Comprendimos los recursos didácticos y técnicos que desde diversas entidades tanto internacionales como nacionales se han producido, con el fin de mejorar las prácticas en las aulas en lo que tiene que ver con la enseñanza de los Derechos Humanos. Hemos dado cuenta de los diversos avances que en materia de $\mathrm{EDH}$, hay tanto a nivel internacional, como desde el punto de vista nacional y a pesar de ello sigue sin responder una pregunta.

Las voces disonantes de uno de los actores del proceso educativo de la EDH, no ha sido suficientemente escuchada, nos referimos a los profesores que han elaborado discursos frente a la $\mathrm{EDH}$, esos que consideran que hay que hacer una enorme critica a las contradicciones inherentes a este discurso y a sus prácticas, los que piensan que la supuesta universalización de los Derechos Humanos es otra manera de enmascarar las desigualdades y las diferencias que subsisten en las sociedades, que se consideran homogéneas por el discurso de los derechos, a los que ven en los Derechos Humanos una verdadera posibilidad contra hegemónica, si este se elabora desde abajo, los que consideran que la escuela no es un escenario adecuado para trabajar EDH, por su estructura jerárquica y en la cual los conocimientos academicistas son los que 
tienen la mayor importancia, aquellos que desde posturas contrarias al establecimiento ven en el discurso de los Derechos Humanos una verdadera posibilidad de cambio estructural para la escuela de hoy o su fin de ser necesario. Esos no son muy escuchados por que sus discursos no hacen parte de las mayorías, es en este sentido que hacemos la siguiente pregunta

¿Cómo se ha configurado el Discurso frente a la educación en Derechos Humanos, por parte de los profesores? Es en este sentido que esta investigación se orienta queremos mostrar si existe dicho discurso y realizar un análisis de su contenido, ¿cuáles son sus aportes a la discusión de la EDH y desde que perspectivas ideológicas, políticas y culturales se orientan para hacer frente a la andanada de propaganda a critica, poco reflexiva y universalista, en una palabra hegemónica frente a la Educación en Derechos Humanos?

Para desarrollar esta investigación los objetivos que permitirán mostrar un panorama general de los discursos elaborados por los profesores frente a la EDH son los siguientes:

- Identificar y comprender cuales han sido los discursos que los profesores han elaborado en torno a la EDH.

- Analizar las diversas perspectivas teóricas que contribuyen a la educación en Derechos Humanos

- Estudiar el contenido y las propuestas que dominan los discursos sobre EDH elaborados por los profesores.

Consideramos que es posible realizar un estudio sobre el discurso que los profesores han elaborado frente a la EDH, desde dos series de documentos como son la revista "Educación y Cultura" de la Federación colombiana de Educadores (FECODE) y el magazín “Aula Urbana" editado por el Instituto para la Investigación educativa y el Desarrollo Pedagógico (IDEP) las dos 
publicaciones se han dedicado desde su nacimiento (la primera a finales del decenio de los ochenta y la segunda a la mitad de los noventas) a difundir los trabajos de investigación tanto teóricos como prácticos, las reflexiones científicas, políticas y culturales que elaboran los profesores en diferentes lugares del país. En este sentido consideramos que en estos órganos difusores del pensamiento de los maestros podemos rastrear cuales han sido las propuestas discursivas elaboradas por los profesores en lo que tiene que ver con la educación en Derechos Humanos.

\section{Metodología del Trabajo}

El análisis de contenido (AC) en un método de investigación que considera la realización de inferencias válidas y confiables partiendo de un contexto estudiado en los documentos que un investigador quiere comprender. Es útil para trabajar procesos de comunicación de contextos como; libros, artículos de prensa, poemas, televisión, grabaciones de videos, fotografías y otros materiales de este estilo. Considera Ruiz Silva (2004) que el AC, es "una herramienta de trabajo que le permite entender mejor al investigador la complejidad de la realidad social ya que puede ampliar el panorama de los fenómenos que se pretenden estudiar” (p. 46-47)

Su uso permite que el investigador pueda descubrir tendencias y diferencias que en el proceso de investigación serán relevantes, comparar mensajes producidos por los actores del proceso comunicativo y que se convierten en objeto de investigación, construir y comparar estándares objetivos en el proceso de la comunicación y descubrir estilos y posturas intelectuales dentro de la comunicación.

Para comenzar se deben codificar las características principales del contenido de las comunicaciones que se quieren analizar (en nuestro caso la revista educación y cultura y el Magazín Aula Urbana) con el fin de realizar un análisis más preciso. 
Para realizar la codificación es necesario definir con antelación el universo de la investigación que se realizara, las unidades de análisis que se tendrán en cuenta y las categorías que contendrán la información a examinar.

En nuestro caso el universo se refiere a las revistas "Educación y Cultura” y el magazín “Aula Urbana” del periodo comprendido entre 1994-2015, la elección del mismo obedece a razones históricas, ya que los avances que en materia de Derechos Humanos se dieron con respecto a la Constitución de 1991, en materia de educación, se comenzaron a desarrollar con la expedición de la ley 115 de 1994, conocida como "Ley General de Educación” que organizo entre otros asuntos la participación democrática y los asuntos de los Derechos Humanos al interior de las escuela; veinte años más tarde es posible y necesario realizar balances de cómo se han desarrollado estos asuntos en las instituciones educativas del país.

En cuanto a las Unidades de Análisis, siguiendo los postulados de Berelson (1971) son cinco las más importantes a saber:

1. Palabra: en donde se mide la cantidad de veces que una palabra es usada.

2. Tema: se crea una oración que encierre un tema y se rastrea su frecuencia en los textos analizados.

3. Ítem: es la unidad de análisis más común y hacen parte de ella los libros, artículos sobre un mismo tema en un medio cualquiera y otro que posean esta misma lógica.

4. El Personaje. Es una persona, de la cual se puede decir cosas sobre sus actitudes y aptitudes.

5. Medidas espacio / tiempo: que son unidades físicas como un periodo de tiempo que puede ser un día, o un periodo de varios años como es nuestro caso. (p.49). 
En lo que tiene que ver con las categorías, los autores proponen una taxonomía que tiene el siguiente orden. Categorías de asunto o tópicos de dirección, de valores, de receptores y físicas. Estas deben cumplir con dos condiciones; por un lado deben ser exhaustivas y mutuamente excluyentes; es decir se deben abarcar todas las sub-categorías que existan y que una unidad de análisis no puede estar en más de una categoría.

En el caso particular de esta investigación hemos decidido analizar el universo de fuentes que ya hemos planteado, mediante la utilización de tres unidades de análisis, que nos permitirán entender cuáles han sido los discursos que han desarrollado los profesores frente a la educación en Derechos Humanos:

La primera tiene que ver con los diversos postulados tanto teóricos como prácticos que han desarrollado o asumido los educadores, con el fin de abordar la tarea de la EDH en sus prácticas pedagógicas diarias; la manera en la cual estas impactan en sus educandos y como han permitido reconfigurar el conocimiento que se crea y recrea en las instituciones educativas en las cuales se desenvuelven los profesores.

La segunda categoría hace referencia a los puntos de vista teóricos y metodológicos que asumen los profesores con miras a desarrollar de ciertos discursos en las aulas de clase y que permiten dar sentido a las prácticas que allí se generan, hacen parte de esta categoría de análisis los objetivos que plantean los educadores a la hora de emprender el camino de la EDH, así como las metodologías que ellos consideran las más adecuadas, los valores que suponen fundamentales para los educandos y la conceptualización de los principios fundamentales que se abordaran en la propuesta. 
La tercera categoría corresponde a tensiones, en ella se consideran las resistencias que el desarrollo de las propuestas encuentran no solo en la escuela como escenario de luchas por la implantación de un determinado presupuesto científico o social, sino que además se trata de dar cuenta de las tensiones internas que tienen los profesores a la hora de emprender este camino, sus propios obstáculos éticos, morales, históricos y culturales entre otros y como a pesar de ellos se realizan programas tendientes a mejorar la práctica de los Derechos Humanos al interior de las instituciones educativas y la sociedad en general.

De esta manera quedan las bases teórico-metodológicas de la investigación expuesta y a lo largo de esta investigación se dará curso a su desarrollo práctico en el estudio de los documentos escogidos como universo del presente trabajo. 


\section{Discurso Pedagógico, Escuela y Derechos Humanos.}

El presente capitulo tiene como propósito descubrir los debates y tensiones en los discursos que hacen parte de los debates enfrentan los maestros y que sirven como soporte teórico al desarrollo de este trabajo, para tal efecto en este apartado se analiza la relación entre Discurso Pedagógico, la Escuela, Derechos Humanos, Educación en Derechos Humanos (EDH), Análisis de Contenido y Discurso pedagógico en Educación en Derechos Humanos

Para comenzar este dialogo con las posturas intelectuales de algunos autores que consideramos representativos, por sus aportes al avance de las ciencias sociales y porque sirven al propósito del presente trabajo de investigación; iniciaremos por proponer una definición del discurso pedagógico que comprendemos como una manera concreta del uso del lenguaje que regula las interacciones entre estudiante-profesor, que contiene una intencionalidad que se materializa en la interiorización de unos conocimientos y que orienta la manera de conocer; así mismo tiene que ver con las especificidades de un tipo de conocimiento y con una manera determinada de la interacción social. En este sentido entendemos el discurso pedagógico como una manera amplia de disertación que no se queda solo en enunciados escritos u orales, en gestos o en determinados acentos que una persona puede imprimir a sus palabras o acciones y que en términos generales tienen que ver con la lingüística y las ciencias que se ocupan del lenguaje.

Para nosotros este discurso fundamentalmente hace referencia a la intervención social ya que todos los seres humanos utilizamos el lenguaje para comunicarnos y este se encuentra inmerso en condiciones sociales y culturales que le proporcionan especificidades de acuerdo a la sociedad a al cual se pertenezca, a la clase social y a la profesión que se ejerza, por lo tanto el discurso puede permitir la reproducción social cuando es producido por individuos o instituciones del Estado o por el contrario puede desarrollar discursos críticos, que tiendan a la emancipación de la 
sociedad, si de su elaboración participan las personas o instituciones de pensamiento crítico y alejadas del establecimiento.

Para Martínez Otero (2007); el discurso pedagógico es la conjugación de la teoría y la práctica, que permite en lo fundamental orientar el proceso de enseñanza aprendizaje; considera que el acto que se lleva a cabo en el aula mediante el discurso pedagógico, tiene ante todo un carácter personal que revela fundamentalmente el perfil del profesor, sus valores y sus esperanzas y que tiene como objetivo situar el camino esencial del estudiante; en esta definición no se hace referencia a las intenciones que tienen los grupos, las clases sociales y el mismo Estado al elaborar el discurso que los individuos apropian y reproducen de distintas maneras, pero que cumplen con una finalidad de permiten la movimiento y reproducción unos discursos sobre otros.

Leal Ladrón de Guevara (2009), reflexiona sobre el carácter tanto común como disímil o divergente, que posee este tipo de discurso, en el sentido que ha hecho parte de todas las culturas humanas, pero que tendrá ciertas especificidades de acuerdo con el contexto de cada pueblo; en tanto acto cultural comunicativo que pretende hacer un intercambio, en este caso de conocimientos, entre un aprendiz y un tutor.

Así mismo considera las características que debe poseer el discurso pedagógico y en este sentido propone que debe ser común a todas las culturas; debe considera y emplea el dialogo intersubjetivo, debe ser un acto que permita y genere el proceso de enseñanza-aprendizaje, se realiza en una práctica que tiene en cuenta el contexto y su habilidad se lleva a cabo en el marco de un sistema educativo 
Martínez (1997) resume de la siguiente manera sus puntos de vista frente al discurso pedagógico; este "Presenta el conocimiento en forma selectiva y gradual, dependiendo de las intenciones del locutor, del conocimiento y necesidades del interlocutor. El discurso pedagógico desfigura en cierta forma el discurso científico con el objetivo de simplificar y hacer una presentación didáctica del texto.” (p.81) La autora considera que son las intenciones de quien construyen este tipo de discurso las que generan la selectividad en los conocimientos y su gradualidad, es decir que cuando se intenta desentrañar las razones que subyacen a una u otra elección de unos contenidos en el discurso, habría que preguntarse por las intenciones de las personas que lo han desarrollado ya que son sus propósitos los que se están poniendo en juego cuando se desarrolla el discurso en el escenario de la escuela.

La profesora Graciela Vázquez (2010), aporta a la discusión sobre el discurso pedagógico considerando que lo fundamental se encuentra en que la interacción que se da entre quien aprende y quien enseña es desigual, en tanto que uno tiene el poder que representa el conocimiento y el otro esta desprovisto del mismo; lo cual hace que se convierta en una herramienta de dominación mutuamente aceptada por las partes que intervienen en el acto educativo. De otro lado, se pregunta por las funciones principales que debe cumplir el discurso pedagógico, en este sentido concluye que este debe efectuar tres; la primera tiene que ver con dar información, es decir que debe permitir que alguien aprenda algo; la segunda tiene que ver con obtener información, esto es que como enseñante me entere de algo y finalmente dar instrucción o que alguien haga lo que como profesor quiero.

Para Rodríguez Gutiérrez (2012), es en la práctica pedagógica en la cual se da origen a la sumisión y al control social, con este autor se pone de manifiesto que existe un discurso pedagógico oficial, que se produce con una intención clara y con el fin de alcanzar ciertos 
objetivos. De otro lado el hecho de que exista un discurso oficial, presupone que haya otro de carácter alternativo que se construye como némesis del primero y que se presupone como su antípoda.

Rodríguez Gutiérrez (2012), a propósito de nuestra discusión considera que habría que analizar hasta qué punto este tipo de discurso se convierte en un mecanismo de poder y control; mediante el cual el profesor somete al estudiante con una serie de prácticas y mecanismos que lo inducen a tomar ciertos comportamientos y a formarse una única manera de relacionarse con el conocimiento; el problema que a nosotros nos parece no tiene en cuenta inicialmente es que en el juego, por decirlo de alguna manera, de concebir el discurso pedagógico el profesor es también una víctima del poder y control ya que quienes controlan la producción, reproducción y el consumo del discurso no son exactamente los profesores, sino las instituciones de poder de la sociedad como los Ministerios y las Secretarias de Educación y algunos intelectuales cuyos discursos han sido legitimados por el aparato del Estado y su disertación sea legitimado ante la sociedad.

Carvajal Aranda, Fajardo Hurtado y Pedraza Quintero (2008) aportan a nuestra cuestión considerando que lo más importante es que el discurso tiene como objetivo fundamental la reconfiguración del conocimiento de las ciencias, con la idea de llevarlo hasta el educando. Los autores consideran que el discurso pedagógico oficial, es más de tipo legal y regulativo; en él están presentes el conjunto de leyes, decretos y normas que desde el Estado se desarrollan para regular la educación y por su puesto su discurso; por el contrario el discurso alternativo que ellos consideran de los intelectuales tiene como fundamento la pedagogía misma y en este sentido haría énfasis en los actores principales del proceso enseñanza-aprendizaje, es decir en el profesor y el educando. 
Bernstein (1984), considera complicado hablar de este discurso debido principalmente a la pluralidad de definiciones que pueden encontrarse y a la enorme cantidad de asuntos de los que trata, ya que el discurso no se puede limitar a un simple código del leguaje, este tiene que ver con las prácticas sociales; en este sentido considera el autor que el discurso tiene como principales objetivos la reconstrucción de un orden determinado y la construcción de un tipo específico de conciencia, es en este punto donde nos brinda su definición del discurso pedagógico en los siguientes términos, "éste puede considerarse como un dispositivo de reproducción de formas de conciencia específica a través de la producción de reglas específicas, que regulan relaciones sociales específicas entre categorías específicas tales como transmisor y adquiriente"(p.3) este discurso está codificado por las relaciones de poder que se establecen entre quienes producen los discursos y quienes los apropian.

Para el autor existen dos tipos de discurso pedagógico uno oficial y otro autónomo; en lo que tiene que ver con el primero considera que, el Estado mediante sus dependencias da origen o asume como propios códigos, reglamentaciones o discursos que dan un orden especifico al mundo escolar "este aparato discursivo legal junto con sus textos administrativos mantiene el control legal y político sobre agentes, agencias, prácticas y discursos requeridos para la reproducción de la cultura de la escuela y la producción de conciencia” (p. 14). En el discurso pedagógico oficial se desarrollaran los principios que el Estado defiende de manera que sean las orientaciones de este las que movilicen los discursos al interior de los centros educativos y así mismo, la visión de mundo, la verdad, los principios y las necesidades del Estado estarán en primer plano a un que no siempre de manera diáfana, en la propuesta discursiva oficial. 
A pesar del poder del Estado para controlar el discurso mediante sus agencias e instituciones, existen diversos grados de autonomía que pueden alcanzar instituciones como las facultades de educación, los institutos científicos y los profesores en la re contextualización de las distintas fuentes de desarrollo del discurso pedagógico y en este sentido no es posible calificarlo siempre y en cada momento de instrumento de propaganda del Estado hacia la sociedad.

Finalmente como el discurso pedagógico se hace mediante el traslado de conceptos de distintas ciencias hacia la pedagogía con el fin de dar a conocer unas determinadas miradas del mundo a los educandos y que esas nociones tienen en sí mismas el sesgo de quienes las eligen; Bernstein (1984) piensa que El Discurso Pedagógico se considera, en este caso, un medio de recontextualización del conocimiento (teórico o común). Al actuar selectivamente sobre el conocimiento que debe transmitirse, al abstraerlo de sus condiciones de existencia y al reenfocarlo, el discurso pedagógico re-enfoca la experiencia de los alumnos, es decir genera nuevas formas de relación social con, y nuevas posiciones en, el conocimiento (p. 35).

Hasta aquí la puesta en común de las representaciones que sobre el discurso pedagógico manejan varios autores, como hemos podido observar la tensión más frecuente tiene que ver con el carácter que posee el mencionado discurso; entre la representación del poder y el control del Estado y por ende tendría más que ver con una disertación que pretende subyugar a quienes participan de este; de otro lado existe la idea que este puede ser entendido en sus propiedades libertarias en tanto permite adentrarse en el conocimiento y con él a una manera de redimirse de las ataduras que propicia la ignorancia. Para nosotros la perspectiva a seguir será como ha quedado claro la del profesor Bernstein, ya que sus contribuciones al tema abordado hasta aquí 
nos permitirán, comprender que tanto de discurso autónomo y que tanto de oficial hay en la configuración del discurso de los profesores frente a la Educación en Derechos Humanos.

A pesar que este tipo de disertaciones se pueden desarrollar en diversos escenarios, de acuerdo a la intensión de quien la realiza; es la escuela el ambiente más adecuada para su desempeño y es por ello que la siguiente categoría que analizaremos es la de escuela.

La escuela como lugar al que asiste normalmente los más jóvenes de una sociedad con el fin de adquirir destrezas en ciertas ciencias y fundamentalmente comprender el desarrollo que ha alcanzado la humanidad en su conjunto en diversos conocimientos, es un proyecto relativamente nuevo podríamos decir que con el advenimiento de las ideas modernas y principalmente con los acontecimientos acaecidos en el siglo XVIII, en Francia, pero que repercutirían en todo el mundo occidental, se puso en marcha un objetivo de ilustración para la escuela; es decir los desarrollos y alcances de la humanidad eran ya tan enormes, que no era posible comunicarlos a las generaciones más jóvenes, sino, por medio de una institución que conscientemente se dedicara a planificar, reconstruir, criticar y dar a conocer lo que la humanidad había logrado en los diversos campos de las ciencias hasta el momento. Esta que algunos consideran es la misión de la escuela, es a mi modo de ver el problema fundamental que afronta hoy la escuela, puesto que las constantes revoluciones científico-tecnológicas han permitido que hoy los más jóvenes puedan tener diversas fuentes de conocimiento más interactivas y claras que lo que puede aportar en ese proceso los profesores, en la escuela.

La escuela, como la entenderemos en este trabajo es la institución en la que es posible crear y re-crear sueños de jóvenes que ingresan a ella con el propósito de aprender lo que las generaciones pasadas han hecho y poder proyectar su propio futuro, es el lugar en el que la felicidad y la dignidad humana deben ser propuestos y reforzados a diario con el fin de conseguir 
seres humanos capaces de comprender el dolor de los otros y comprometerse a cambiar el mundo para que cada día sea más humano y en el que podamos vivir todos. En este sentido la escuela no debe tener una visión nacionalista de la historia, no debería estar comprometida con un tipo de valores morales, ni con una religión, tampoco debe convertirse en un instrumento de dominación ideológica, ni en la punta de lanza de la propaganda del Estado o de una clase social.

La escuela debe ser emancipadora, debe estar comprometida con todos los seres humanos con sus proyectos de vida y con el desarrollo de su dignidad, debe estar siempre comprometida con el logro de la felicidad humana representada en la felicidad personal de todos los seres humanos.

Desde la segunda mitad del siglo XX, se han presentado sendas críticas a la escuela, en las cuales se la muestra como una institución conservadora, que promueve los valores de las clases dominantes y que a pesar de su discurso en contra de los privilegios, los promueve desde lo que se conoce como el currículo oculto, muchos intelectuales han considerado que la escuela ha fracasado en sus propósitos y que esta debería acabarse o reformarse. Una de las críticas más importantes es la que hace Michel Foucault, (2003) quien considera que una vez la educación descubrió el cuerpo como objeto de poder, lo educa para obedecer y lo hace dócil. En este sentido este autor nos muestra en la figura del soldado la manera en la que el dominio y disciplinado sobre el cuerpo hace de este una especie de aparato dispuesta a obedecer "se ha hecho la máquina que se necesitaba; se han corregido poco a poco las posturas; lentamente, una coacción calculada recorre cada parte del cuerpo, lo domina, pliega el conjunto, lo vuelve perpetuamente disponible" (p. 124).

El adiestramiento que reciben los soldados en las instituciones militares los hace ser obedientes y dóciles ante las órdenes de los superiores, los hace disciplinados. Para Foucault este 
tipo de docilidad, obediencia y disciplina, se desarrolla en instituciones tales como la familia, la fábrica, la religión y por supuesto la escuela, ya que en todas es posible encontrar las condiciones ideales que permitirían construir cuerpos obedientes "Es dócil un cuerpo que puede ser sometido, que puede ser utilizado, que puede ser trasformado y perfeccionado" (Foucault 2003, p.225). Los procesos de enseñanza-aprendizaje, transforma, perfecciona, utiliza y somete el cuerpo y la mente de los educandos mediante una serie de tecnologías (ejemplos de ello pueden ser la ida de los jóvenes al baño y el timbre para cambiar de clase) que generan relaciones de poder, entre los diversos actores en el interior de la escuela.

Otra crítica Importante a la escuela como estrategia de reproducción, es decir en tanto manera en la que la sociedad organiza la continuidad de unas ideas, una manera de relacionarse con el poder, unos cánones de belleza y en fin una cultura; es la que plantea el sociólogo francés Pierre Bourdieu (1996), quien considera que la escuela es algo así como una fábrica de humanos en tanto que formas de pensar y de actuar, "la escuela opera la imposición de la cultura dominante, establece unas jerarquías y enmascara la realidad de las relaciones sociales.” (p. 9). Considera este autor que la escuela es la "principal instancia legítima de legitimización de lo arbitrario cultural que contribuye a la reproducción de la estructura de la distribución del capital cultural entre las clases y, su trámite, a la reproducción de las relaciones de clase existentes.” (p. 17). Ya que la escuela goza de legitimidad entre las diferentes clases tiene el poder de decidir que es genuino enseñar y aprender.

La escuela contribuye a las diferenciaciones sociales cuando, las disfraza de diferencias escolares haciendo que aquellas parezcan naturales, por lo que para Bourdieu la escuela es un escenario en el cual se continúan y se perpetúan las desigualdades sociales disfrazándolas de diferencias naturales. En este sentido la entiende como "La escuela es, por lo tanto, la institución 
investida de la función social de enseñar y por esto mismo de definir lo que es legítimo aprender. La escuela, legitima de tal manera la arbitrariedad cultural.” (Bourdieu, 1996, P. 18).

En este mismo sentido de comprender la escuela como dispositivo hegemónico mediante el cual la se propagan verdades, valores, intencionalidades y formas de ser y actuar en la sociedad se encuentran los aportes de Hernún (2007), para quien la escuela está pensada como dispositivo de encierro, de la misma naturaleza que la cárcel y el sanatorio, de quienes se diferencia por la población a la que se dedica que en su mayoría son niños, niñas y adolescentes.

Este autor considera que existen tres tipos de críticas a la escuela; la sistémica que tiene que ver con las deficiencias estructurales de un sistema educativo para conseguir los mejores resultados en lo que tiene que ver con programas, presupuestos y posiciones políticas, en ella no se hace una profunda critica a la escuela como arma de dominación de una clase sobre otra o como una de las maneras privilegiadas en las que un régimen puede ideologizar a una sociedad. La segunda tiene que ver con lo académico y en esta se hace énfasis en el diseño curricular, la didáctica, las orientaciones pedagógicas, las relaciones educador educando y la tercera es la más radical y tiene que ver con la estructura general de la escuela; esta considera la escuela en términos de la función social que cumple y en este caso considera que debe ser reformada desde la pedagogía y las practicas profesores.

Siguiendo en esta misma línea de argumentación se encuentra Iván Illich, (1985), para quien la escuela se percibe "...como el proceso que especifica edad y se relaciona con maestros, y exige asistencia a tiempo completo a un currículum obligatorio...La escuela es la agencia de publicidad que le hace a uno creer que necesita la sociedad tal como está.”(p.17). Para este autor la escuela debería desaparecer ya que lo más importante que aprendemos los seres humanos; lo hacemos por fuera de la escuela, en este sentido distingue claramente entre escolaridad y 
educación, haciendo hincapié, en la capacidad liberadora o emancipadora que tiene la segunda; por encima de la facultad de mantener los privilegios que lleva implícita la primera.

Paulo Freire en una conferencia dictada en Argentina en la década de los ochentas considero que la escuela es:

El lugar donde se hacen amigos. No es edificios, salas, cuadros, programas, horarios, conceptos. Escuela es, sobre todo, gente. Gente que trabaja, que estudia, que se alegra, se conoce, se estima. El/la directora es gente. El/la coordinador/a es gente, el profesor, la profesora es gente, el alumno, la alumna es gente, y la escuela será cada vez mejor en la medida en que cada uno/una se comporte como colega, como amigo, como hermano. Nada de islas cercada de gente por todos lados. Nada de convivir con las personas y descubrir que no se tiene a nadie como amigo. Nada de ser como block o ladrillo que forma la pared. Importante en la Escuela no es solo estudiar, no es solo trabajar, es también crear lazos de amistad. Es crear ambientes de camaradería. Es convivir, es sentirse "atada a ella". Ahora, como es lógico.... en una escuela así va ser fácil estudiar, trabajar, crecer, hacer amigos, educarse, SER FELIZ. Es así como podemos comenzar a mejorar el mundo. (Freire, 2011. blogspot).

Esta visión positiva, de la escuela surgió del compromiso y la comprensión de la escuela como elemento de emancipación, que tienen los sectores populares de la sociedad, de la escuela como constructora de proyectos de vida que conduzcan a la felicidad de los seres humanos y a la realización de la dignidad humana La discusión sobre el significado de la escuela es muy intensa ya que este es uno de esos conceptos que no permiten posiciones neutras; por ello es muy difícil generar puntos de encuentro entre quienes la defienden como institución que permite la emancipación humana en tanto que en ella los seres humanos reconocen las realizaciones que 
como especie hemos conseguido y con ellas como base se pueden proyectar los más inverosímiles proyectos de vida tanto individuales como colectivos y quienes la atacan como establecimiento de dominación y mantenimiento del estatus quo, de una sociedad mediante la imposición de pautas de conducta a los individuos que asisten a ella.

Pese a ello nos interesa en este trabajo la posición de paulo Freire, con quien compartimos una mirada de esperanza sobre la escuela, sin dejar de lado las críticas que tienen que ver más con los objetivos que se le han impuesto a ella en el marco de la modernidad o con las frustraciones que en su interior pueden terminar desarrollándose en los estudiantes. Sin embargo el potencial liberador y constructor de la escuela es el que más nos in teresa destacar en este apartado y en este punto es donde tiene cabida el desarrollo conceptual de los Derechos Humanos, en cuanto practica liberadora y esperanzadora para la humanidad.

El desarrollo histórico del concepto de Derechos Humanos puede ser rastreado hasta muy atrás en la historia de las civilizaciones humanas; se pueden conectar acontecimientos y lugares de distintos puntos geográficos; con el fin de mostrar la manera en la cual las sociedades se han dotado a sí mismas de ciertos derechos y la forma en la cual estos se hicieron cada vez más amplios cubriendo a mas grupos y más espacios de la vida. Sin embargo fueron los acontecimientos sobrevenidos entre la primera y la segunda Guerra Mundial los que se consideran como una ruptura fundamental que hizo que se desarrollara un consenso político y una serie de instrumentos del derecho internacional con el fin de evitar la extinción de la especie humana que con el desarrollo tecnológico había conseguido fabricar sistemas masivos y sofisticados de dolor y extinción como nunca se había visto; por ello fue luego de que termino la Segunda Guerra Mundial, cuando se creó la Organización de las Naciones unidas y unos pocos 
años después se dio vida al documento marco la Declaración Universal de los Derechos Humanos.

En la actualidad existen diversas orientaciones intelectuales para vislumbrar los Derechos Humanos, podemos comprenderlos desde la visión del iusnaturalismo, desde el utilitarismo, el neo-contractualismo y la ética discursiva, entre otros. Sin embargo, para efectos de esta investigación nos referiremos a los autores que pensamos nos permiten comprenderlos como exigencias sobre todo morales en la sociedad actual.

Algunos teóricos consideran los aportes del filósofo alemán Jürgen Habermas, para las personas que razonan los Derechos Humanos desde esta perspectiva, estos son entendidos como normas morales que serán aceptados solo por una Comunidad de Dialogo, solo a si es posible universalizar los conceptos porque son aceptados por la mayoría de la comunidad discursiva,

Sin embargo este dialogo debe tener una serie de requisitos fundamentales que legitiman el resultado: todos los participante en el dialogo deben tener los mismos derechos y las mismas posibilidades de defender sus posturas, estando prohibida la coacción, y el objetivo del dialogo debe ser el llegar a un acuerdo. (Mestre Chust, 2005, p.4).

De otro lado los filósofos alemanes Menke y Pollmann (2010) consideran que existen dos maneras de entender los Derechos Humanos entre los pensadores minimalistas y los maximalistas; los primeros piensan que el contenido que se debe garantizar debería ser mínimo para que por ello mismo pueda ser más amplia su aceptación por parte de las distintas sociedades; por otro lado los maximalistas piensan que el contenido que se debe garantizar debe ser lo más amplio posible; con el fin de garantizar una convivencia democrática mayor; en este sentido los autores consideran que “...Esta diferencia entre una concepción conscientemente 
limitada y otra más amplia de los Derechos Humanos nos acompañara ...pues el cara a cara entre una interpretación minimalista y otra maximalista es un signo fundamental del debate actual sobre los Derechos Humanos" (p.42).

Algunos autores hacen hincapié en unas facultades y unas instituciones que tienen como principios la realizan las aspiraciones más profundas de la humanidad en cada época; las cuales tienen que ver con la dignidad, la libertad y la igualdad. Su acento especial en que esas instituciones deben contribuir a su logro independiente de la época es lo que nos cuesta comprender ya que la experiencia histórica humana nos muestra que la norma general ha sido la negación de los derechos o mejor su inexistencia absoluta para la mayoría de los seres humanos y que este tema siempre ha sido de elites de distintos órdenes.

En el Preámbulo de la Declaración Universal de los Derechos Humanos se lee "Considerando que la libertad, la justicia y la paz en el mundo tienen por base el reconocimiento de la dignidad intrínseca y de los derechos iguales e inalienables de todos los miembros de la familia humana" (ONU 1948, parr.1) nos damos cuenta que para la ONU, los Derechos Humanos parten del reconocimiento de la dignidad de todos los seres humanos sin ningún tipo de restricciones al respecto, en este sentido la ACNUR considera que “...los Derechos Humanos pueden definirse como los derechos inherentes a nuestra naturaleza, sin los que no podemos vivir como seres humanos" (ACNUR, 2004).

En esta misma línea argumentativa se encuentra el Ministerio de Educación Nacional (MEN 2006), en donde se comprenden los Derechos Humanos como un conjunto de bienes que poseen un carácter universal, en el sentido de pertenecer a todos sin distinciones, pero que se deben ubicar de manera contextual de acuerdo a las representaciones culturales de cada pueblo; además son un código de conducta por el cual todos debemos regirnos, que está vivo en la idea 
de que no se encuentran estáticos y que todos sin excepción son inalienables interdependientes e indivisibles, lo cual permite que las comunidades siempre puedan exigir del Estado su cumplimiento integral.

Por otro lado desde el siglo XIX, a la par con el impulso dado a las disertaciones sobre los derechos principalmente en las sociedades occidentales, se han escuchado voces discordantes en contra de los Derechos Humanos, hay que recordar la crítica que hizo de estos Carlos Marx, en la Cuestión Judía, al considerar que el Estado al ser una representación de una clase dominante no tiene el potencial para realizar la emancipación de los seres humanos mediante los derechos; ya que este contribuiría a ahondar las desigualdades sociales; mediante el encubrimiento de las difíciles condiciones materiales de la clase obrera.

En el mundo contemporáneo tenemos pensadores como De Sousa Santos (2002), quien se interesa por lo que él considera el carácter emancipatorio de los Derechos Humanos y la manera en la que se podría lograr, considera este autor que existen al menos dos maneras de entender los Derechos Humanos "los Derechos Humanos... pueden ser concebidos o bien como una forma de localismo globalizado o como una forma de cosmopolitanismo o, en otras palabras, como una globalización desde arriba o desde abajo" (p. 66).

Desde la perspectiva de De Sousa santos (2002), habría que transformar el pretendido universalismo de los derechos, por una dialogo intercultural que permita dejar de lado una concepción desde arriba de los Derechos Humanos y le proporciones su fuerza emancipadora desde un "Cosmopolitanismo desde abajo como un dialogo intercultural que permite contrarrestar la hegemonía frente al discurso de los Derechos Humanos" (p.68). De esta manera se podría conseguir un dialogo intercultural que permita llegar a una nueva visión de los 
Derechos Humanos, a la cual se puedan suscribir más culturas por un carácter más democrático y amplio de los mismos.

Los actuales críticos de una concepción estrecha de los Derechos Humanos como Pollmann (2008), consideran que "El concepto de Derechos Humanos se refiere a las pretensiones justificadas que todo hombre tiene a vivir en determinadas condiciones, sin depender de que el Estado al que pertenece haya contraído obligaciones jurídicas al respecto.” (p. 13). En este sentido no interesaría que el Estado al cual pertenezca una persona no haya, incorporado los Derechos Humanos en su ordenamiento jurídico interno, está obligado de igual manera a garantizar las condiciones que le permitan a sus ciudadanos expandir sus condiciones de vida; es desde esta perspectiva que se considera que "Los Derechos Humanos se ofrecen en nuestra época como una «moral mínima» que pretende tener alcance universal y hacer las veces de una instancia normativa que nos permita orientar (humanizar) la conducta social e individual.(p.10).

Desde allí el autor reconfigura la definición, para finalmente proponernos la siguiente "Los Derechos Humanos son pretensiones (aspiraciones), moralmente fundamentadas, a realizar políticamente derechos fundamentales" (Pollmann. 2008, p. 12), en ella combina los aspectos morales, jurídicos y políticos de los Derechos Humanos y amplía la categoría

Por otra parte tenemos a Thomas Pogge (2005) quien se podría insertar entre los autores que defienden la postura minimalista ya que para él:

Los Derechos Humanos se entienden como aquellos derechos muy básicos que tiene todo ser humano. En virtud de estos derechos, cada ser humano goza de cierta protección moral mínima para no ser tratados de determinada manera por otros agentes humanos, 
sean individuales o colectivos. Y en virtud de estos derechos, cada ser humano también goza de cierta protección moral mínima contra la imposición de determinadas leyes o prácticas sociales. (Párr.1).

Las tensiones que se destacan en lo que tiene que ver con el concepto de Derechos Humanos, hacen referencia principalmente a las dificultades a la hora de considerar los derechos como inherentes a todos los seres humanos por el solo hecho de haber nacido ya que algunos autores consideran que ha sido mediante las luchas sociales como se ha conseguido el surgimiento de estos y por lo mismo no se podría concebir que se posean per se. Es explicita la tensión entre quienes defienden el universalismo de los derechos y quienes ven en esto una manera de imposición incluso autoritaria de la cultura occidental y pretenden hablar de diálogos entre iguales en los cuales no es posible hablar de absolutos inamovibles; existe una tensión entre los que consideran a los Derechos Humanos como un asunto que tiene que ver mayoritariamente con cuestiones jurídico políticas y quienes los conciben ante todo como una propuesta ética y moral y desde allí proponen su transformación y su exigibilidad. Desde esta perspectiva, podemos entender la importancia que tiene una $\mathrm{EDH}$, que contribuya desde las primeras edades a comprender la discusión sobre la dignidad como característica esencias le la humanidad.

La educación en Derechos Humanos hace parte hoy del discurso oficial, las principales agencias internacionales que tienen que ver con los Derechos Humanos han hecho aportes frente al tema de la EDH, en este sentido las Organización de Naciones Unidas (1995) hace énfasis en los procesos de transformación de los comportamientos humanos, encaminados a generar una cultura de paz, respeto y tolerancia entre todos los miembros de la familia humana; así mismo en que existen los mecanismos legales idóneos en el derecho internacional de los Derechos Humanos, para que se haga respetar la dignidad humana; sin la necesidad de recurrir dispositivos 
fuera de la ley. Para las Naciones Unidas la EDH, (ONU A/51/506/Add1, apéndice, párr. 2). Se debe constituir en un proceso que dure toda la vida y en el cual el profesor no puede limitarse a suministrar a los educandos la información sobre los mismos, puesto que se privilegian el enfoque reflexivo y vivencial.

Por otro lado Tunnermann Bernheim (1999), considera que la EDH, tiene que ser considerada como un principio superior que debe impregnar siempre el ejercicio profesor en este sentido se concibe como una propuesta no solo a largo plazo, pero además transformadora de la sociedad humana en su conjunto y que no es posible trabajar como asignatura; sino como forma de ser y vivir entendida e interiorizada y sobre todo defendida por los educandos.

La declaración de México sobre educación en Derechos Humanos en América Latina y el Caribe; que fue el producto final de la reunión realizada a finales del año 2001, en el Distrito Federal y a la cual asistieron diversas organizaciones tanto internacionales como nacionales, de carácter público y privado y en cuyo objetivo principal estaba examinar en qué estado se encontraba la $\mathrm{EDH}$, a nivel de toda la región aporto muchos datos sobre el desarrollo del tema a nivel de todo el subcontinente y un aporte fundamental es considerar "Que la educación en Derechos Humanos es en sí un derecho fundamental” (Anuario de Pedagogía. 2001, p. 82 ) Esta concepción pone de manifiesto la importancia que el tema de la EDH, ha suscitado en diferentes espacios tanto académicos, sociales, políticos y culturales de América Latina.

En la declaración se hace un análisis histórico sobre la gestación, la consolidación y la actualidad del tema de la Educación en Derechos Humanos en América Latina y el caribe; considerando de la misma manera que la mayoría de estudiosos del tema que esta se inició en el decenio de los ochentas, teniendo como objetivo el trabajo sobre el derecho a la vida y el acompañamiento de la transición la democracia de algunos países de la región, en este sentido 
consideran que el inicio de la EDH, en el sub continente se dio de manera accidentada y fue más el interés de ciertas organizaciones de la sociedad civil y no una práctica legitimada desde las instituciones del Estado.

Consideran que durante el decenio de los noventa la EDH, consiguió la legitimación institucional, mientras que las temáticas desarrolladas se diversificaros, así mismo como los actores sociales a los que iba dirigida su acción. De esta manera ingresaron nuevas preocupaciones para los educadores dedicados a trabajar por la EDH y amplio el público al cual se dirigía.

Con el advenimiento del siglo XXI, los retos para la EDH, pasan por lograr el empoderamiento de las personas y el desarrollo de una cultura democrática que defienda y promueva los Derechos Humanos en la región. Las temáticas continúan ampliándose y hoy se trabajan problemas tales como la concentración excesiva de riquezas en pocas manos en la región, la corrupción; la impunidad; la desigualdad en el acceso a la justicia; el desempleo; el déficit de vivienda, salud y alimentación; los cuales generan criminalidad e inseguridad en nuestra región y limitan la participación de la mayoría de la sociedad en la toma de decisiones que la afectan, debilitándose con ello los procesos democráticos y el goce de los derechos.

El Ministerio de Educación Nacional (MEN 2006) considera que la EDH, en el ámbito de la educación formal involucra tanto la práctica como la vivencia de los Derechos Humanos en la cotidianidad de la escuela, transformando las practicas pedagógicas con la idea que ellas deben partir de los contextos en los cuales viven y se mueven los educandos para realizar la acción educativa; para el MEN la línea a seguir debe ser la que se prioriza en los acuerdos internacionales y su apuesta principal se encuentre en las competencias ciudadanas y en el Plan Nacional de Educación en Derechos Humanos. 
Por otro lado el Instituto Interamericano de Derechos Humanos (IIDH, 2006) organismo de consulta de los gobiernos de la región en materia de EDH, considera que esta debe tener como propósito la adquisición por parte de los educandos de unos conocimientos, valores y habilidades que son necesarios;

para conocer, comprender, afirmar y reivindicar los propios derechos, sobre la base de las normas dispuestas en los distintos instrumentos internacionales en conexión con la normativa interna, es decir, no es una traslación mecánica de “conocimientos, habilidades y valores", sino que es un libro abierto, un edificio en construcción, es vida humana objetiva, es cultura (p. 19).

Acerca de la EDH el Plan Nacional de Educación en Derechos Humanos (PLANEDH. 2010) considera que esta debe permitir hacer conciencia en los educandos de la manera en la que se establecen las relaciones entre la sociedad civil y los Estados, permitiendo que se entienda la complejidad que estas encarnan y los conflictos que pueden estallar, así mismo debe encargarse de hacer realidad la vivencia de la dignidad humana como principio rector del respeto en las sociedades actuales.

En otro sentido existe un enfoque que podríamos llamar crítica frente a la EDH, el cual tiene uno de sus principios en la Pedagogía Crítica y principalmente en el pedagogo brasilero Paulo Freire; esta dirección adquiere relevancia puesto que propone una educación centrada en el contexto y las vivencias de los educandos y en la vida misma de los participantes de la experiencia educativa; desde esta perspectiva el conocimiento no está en cabeza del profesor, sino que este se hace y rehace en la vivencia, en el hacer, en el trasegar de la práctica y entre los 
participantes y es en este punto donde rompe con la concepción más formal de la EDH, en la cual esta se convierte en una especie de recetario que no responde muchas veces a ninguna de las preguntas fundamentales que se hacen los educandos. Según Espinel Bernal (2010) las prácticas pedagógicas que se orientan desde los principios críticos freirianos desarrollan ciertas características que él denomina categorías emergentes las cuales permiten analizar el trabajo que proponen las experiencias educativas y a la vez caracterizarlas; en todas ellas se plantea una formación ético-política que desde la perspectiva de la EDH, significa que toda ejercicio pedagógica, es ante todo política y por lo tanto legitima o transforma las prácticas sociales; mediante el afianzamiento de una posición crítica de los estudiantes frente a la sociedad y a los discursos que en ella circula.

La EDH, en este sentido considera la Constitución de las subjetividades de los educandos mediante un estudio de la cultura en la cual se encuentran inmersos tanto los estudiantes como los educadores, haciendo hincapié en la posibilidad de cambiarla encontrándole nuevos sentidos al mundo; es decir que no es suficiente con la comprensión de la vulneración permanente de los derechos, la labor del profesor es ir más allá generando en los colegiales una sensibilidad distinta en la cual se entienda a los otros como iguales a mí y por tanto entendiendo que todo lo que le pasa a un ser humanos me debe afectar esencialmente por hacer parte de la familia humana.

Desde la perspectiva crítica, se busca que el conocimiento no sea una especie de letra muerta, por ello se considera que la EDH debe tener un carácter comunitario, en este sentido el trabajo debe tener su fuente en las realidades vividas en las comunidades, con el fin que los educandos vivan, interioricen y defiendan los Derechos Humanos como propios.

Se comprende a los jóvenes como sujetos políticos; a partir de procesos de empoderamiento que permitan que sean los jóvenes quienes lideren las transformaciones sociales 
que requieren sus comunidades, con lo cual cambia la percepción que generalmente se tiene sobre ellos en las comunidades que generalmente es negativa. Finalmente se hace ahínco en la eficacia del proceso de formación que se hace efectivo mediante la solidaridad que se desarrolla entre los participantes quienes asumen las dificultades de las otras como propias y propician escenarios de cambio para todos.

En este mismo sentido de considerar la EDH como una alternativa pedagógica se encuentra Rodríguez Heredia (2015) quien a propósito de reflexionar sobre tres experiencias en EDH concluye que algunas de ellas logran contradecir su propio origen, en el sentido que su comienzo está atravesado por los principios y necesidades de los organismos internacionales (ONU, OEA entre otros) y las urgencias y conveniencias de los Estados nacionales y a pesar de ello se plantean como disyuntivas capaces de intervenir y transformar la vida de las comunidades y con la potencialidad de auto determinar su camino. Considera este investigador que con el fin de consolidarse como alternativa la EDH debe considerar reformular tres premisas que le ha impuesto hasta ahora su gestación como herramienta de masificación de una versión (la de las potencias y las elites) de los Derechos Humanos; la primera tiene que ver con la consideración de la democracia liberal como el mejor sistema político y de participación que existe y por lo tanto como el que debe ser impuesto en los países en los cuales se defiende los Derechos Humanos; la segunda hace referencia a la idea de sujeto de derecho como referente del individualismo que deshumaniza y considera todo incluido el ser humano como una mercancía y finalmente una EDH que se considere así misma como alternativa debe ser capaz de entender der el conflicto social como inherente a la humanidad y el uso de la fuerza como componente de las relaciones sociales. 
Hasta aquí la disertación sobre la EDH, de la cual nos quedan como principal tensión la que tiene que ver con lo que podríamos llamar la perspectiva formal de esta, que es la que se expone desde los organismos internacionales como la ONU, la UNICEF o la OEA y que tiene que ver con la reproducción des sistema democrático liberal, basado en los principios de individualización y el reconocimiento de la propiedad privada y la libertad individual; como los fundamentos de las sociedades modernas

Por otro lado se encuentra lo que hemos llamado una EDH desde una configuración critica; esta considera que lo fundamental no es trabajar desde los derechos como principios rectores de la educación, por el contrario se plantea la idea de retomar y analizar el contexto en el cual se ven inmersos los educandos para desde allí generar las reflexiones que conduzcan a los educandos a la revaloración de los derechos y a la toma de conciencia sobre la importancia de los mismos en las sociedades actuales; en estas reflexiones subyace una idea que considera que los Derechos Humanos son ante todo reivindicaciones que contiene un carácter principalmente ético-moral, sobre lo político-jurídico

Una tensión que se hace evidente es lo que los pedagogos de la escuela critica llamarían la praxis; es decir la dificultad de llevar a las aulas el discurso que se ha elaborado de forma cuidadosa y que por diversas razones (como pueden ser el desconocimiento del contexto, la falta de interés o la sub valoración de los participantes de la experiencia pedagógica) no alcanza a conectarse con la práctica de los profesores en sus aulas y por ello mismo no se obtienen los retos que dichas prácticas pretenden. Una de las posibilidades de análisis con las que se puede esclarecer este asunto podría ser entender cuáles son los discursos que han propuesto los profesores sobre la EDH puesto que estos nos permitirán comprender las tensiones propias de aquellas disertaciones y como afectan las prácticas que se llevan a cabo en el aula; es en este 
punto que se torna relevante el Análisis de Contenido (AC) como metodología de la investigación puesto que nos permitirá entender el alcance de los discursos de los profesores frente a la EDH y cómo afectan sus prácticas.

En lo que tiene que ver con el Análisis de Contenido (AC), son muchos los estudios que sobre el tema se han desarrollado e innumerables las definiciones que se han aportado

El trabajo realizado por Andreu Abela (2001), en el cual se hace un examen de la propuesta metodológica frente a lo que es el Análisis de Contenido desde una perspectiva historiográfica considera como padre de esta propuesta al sociólogo estadounidense Bernard Berelson quien pensaba que este es "una técnica de investigación para la descripción objetiva, sistemática y cuantitativa del contenido manifiesto de la comunicación.” (p. 2) Para este investigador lo fundamental es que los procedimientos puedan ser verificados por otros, que tenga un orden claro y definido; por lo que no podrían trabajarse estudios cualitativos mediante esta técnica. Por su parte Hostil y Stone (2001) al tratar el tema concluyeron que "El análisis de contenido es una técnica de investigación para formular inferencias identificando de manera sistemática y objetiva ciertas características específicas dentro de un texto”. (p. 3) Estos autores avanzan en el sentido de dar cabida a la posibilidad de utilizar el Análisis de Contenido, en investigaciones cualitativas y además consideran que lo fundamental es este tipo de estudios deben ser las deducciones que de ellos se desprendan.

Krippendorff, amplia el campo de trabajo del Análisis de Contenido al considerar que este es "una técnica de investigación destinada a formular, a partir de ciertos datos, inferencias reproducibles y válidas que puedan aplicarse a su contexto" (Andreu J 2001, P. 4). Este autor considera el contexto en el cual se fabrican los mensajes como fundamental a la hora de realizar 
el análisis de contenido; además piensa que las conclusiones que saca el investigador se deben aplicar al contexto.

Para Bardin lo fundamental del Análisis de Contenido estaría en;

El conjunto de técnicas de análisis de las comunicaciones tendentes a obtener indicadores (cuantitativos o no) por procedimientos sistemáticos y objetivos de descripción del contenido de los mensajes permitiendo la inferencia de conocimientos relativos a las condiciones de producción/recepción (contexto social) de estos mensajes (Andreu 2001, p. 5).

Por su parte Andreu Abela (2001), propone que se debe considera que el Análisis de Contenido (AC) se trata de;

Una técnica de interpretación de textos, ya sean escritos, grabados, pintados, filmados..., u otra forma diferente donde puedan existir toda clase de registros de datos, trascripción de entrevistas, discursos, protocolos de observación, documentos, videos,... el denominador común de todos estos materiales es su capacidad para albergar un contenido que leído e interpretado adecuadamente nos abre las puertas al conocimientos de diversos aspectos y fenómenos de la vida social" (p.6).

Para él lo fundamental estriba en que este tipo de planteamiento metodológico debe contribuir a realizar explicaciones que den cuenta desde el análisis textual de la vida social.

Para el sociólogo Piñuel Raigada (2002) se trata en lo fundamental de un Conjunto de procedimientos interpretativos de productos comunicativos (mensajes, textos o discursos) que proceden de procesos singulares de comunicación previamente 
registrados, y que, basados en técnicas de medida, a veces cuantitativas (estadísticas basadas en el recuento de unidades), a veces cualitativas (lógicas basadas en la combinación de categorías) tienen por objeto elaborar y procesar datos relevantes sobre las condiciones mismas en que se han producido aquellos textos, o sobre las condiciones que puedan darse para su empleo posterior (p. 2).

En este sentido se hace hincapié en la capacidad que dicho procedimiento tiene para develar las condiciones sociales y culturales en las cuales fueron desarrollados dichos documentos; en este sentido podríamos decir que su importancia radica en hacer hablar a las fuentes de lo que los autores no querían o no les parecía importante y revelar u conocimiento renovado sobre las citadas fuentes.

Finalmente el profesor Ruiz Silva (2004) Considera que estamos frente a una herramienta de trabajo que le permite entender mejor al investigador la complejidad de la realidad social ya que puede ampliar el panorama de los fenómenos que se pretenden estudiar (p. 45). El Análisis de Contenido establece una conexión entre tres grados del lenguaje "el de superficie...el analítico y el interpretativo" (p. 46-47) que van desde la información sin ningún tipo de tratamiento, pasando por la organización de criterios para reunir la información y hasta la reorganización de conclusiones que permitan generar un conocimiento más profundo o nuevo sobre la realidad revelada desde las fuentes.

En cuanto al Discurso Crítico de la Educación en Derechos Humanos (DCEDH) consideramos que este debe partir de alejarse de las posturas dominantes frente a los Derechos Humanos (iusnaturalismo, contractualismo, utilitarismo o positivismo jurídico) que consideran que estos son tanto universales como obvios, (por ser estos el producto de la razón humana) objetivos y extendidos a todos (por hacer parte de la familia humana) que además no son 
problemáticos ni ambiguos. Por el contrario el (DCEDH) debe partir de comprender que aquellos son controversiales en sí mismos y debatibles por los demás; que estos no poseen un carácter incuestionable; debe hacer evidente siempre la tensión existente la Universalidad y la particularidad y no realizar generalizaciones taxativas.

Una aproximación crítica de la $(\mathrm{EDH})$ debe tener en cuenta que a pesar del desarrollo tanto teórico como discursivo los Derechos Humanos se encuentran en crisis tanto conceptual como cultural y que esta puede identificarse en la extensa vulneración que se hace en el mundo entero y en la manera en la cual estos se han convertido en el discurso legitimador de mayores niveles de violencia e injusticia en el mundo. El (DCEDH) debe generar conciencia de la manera en que estos son manipulados y como su práctica se ha instrumentalizado, al punto de no significar mucho más que otro discurso legitimador de odios y violencias en contra de algunos pueblos, la manera en la cual hoy se han convertido en una práctica discriminatoria usada por las potencias occidentales, para intentar dominar a quienes no los consideran como parte de sus prácticas sociales. Debe alejarse de la concepción juridicial que ha dominado tanto su práctica como su enseñanza y comprenderlos desde un punto de vista tanto ético como moral, como compromiso de todos los seres humanos para con el planeta y todas las especies que en el habitamos.

Con el proceso de globalización económico, social y cultural, acelerado desde mediados del siglo XX, se ha desarrollado la concepción universalista de los Derechos Humanos en tanto imposición de una cultura sobre otras, dejando de lado la idea de estos en cuanto potencial, es decir que podríamos ir construyendo un discurso en el cual cupiéramos todos los seres humanos en tanto miembros de la misma especie mediante consensos y disensos; en este sentido el DCEDH, debe tener en cuenta que la escuela está colmada de minorías capaces de desarrollar sus 
potencialidades y darnos lecciones de tolerancia y trabajo en equipo, sin necesidad de imponer unos criterios o una visión particular de hacer las cosas.

La multiculturalidad reivindica espacios de dialogo con los discursos hegemónicos, en los cuales se construyan relatos novedosos de la ciudadanía, sin imposiciones desde ningún lugar y es allí donde la escuela y la EDH, deben tener una visión más amplia y critica en la cual se privilegien el pluralismo y la heterogeneidad sobre el universalismo y la homogeneidad.

Por otro lado el DCEDH, debe considerar que el proceso de enseñanza-aprendizaje parte de la experiencia real de los educandos y los educadores; que no se trata exclusivamente de la acumulación de unos contenidos, para luego dar cuenta de ellos así sea en ejercicios bastante parecidos a la realidad, pero que lo fundamental es la praxis (teoría-practica) frente a los Derechos Humanos. Siempre se debe recordar el potencial emancipador y de exigibilidad que hace parte esencial de aquellos; generando nuevas manera de pensar la ciudadanía, ampliando este concepto para que en él quepan cada vez más personas; pensando en alternativas de lucha y exigibilidad de los derechos y aportando a la creación de amplios espacios democráticos.

Hasta aquí hemos hecho evidentes los debates y las tensiones que subyacen a los diversos postulados teóricos que hacen parte de esta investigación; hemos dado cuenta de cómo la EDH, adquirió relevancia como el instrumento preferida por los organismos multilaterales dedicados a la divulgación y promoción de los Derechos Humanos, así como por las agencias de los Estados consagradas a nivel nacional de realizar esta misma labor; hemos visto como mediante la implementación de los postulados de la pedagogía critica la EDH, se convirtió en unos casos en alternativa pedagógica y en otros en un orientación critico frente a los postulados tradicionalistas que se defendían desde los organismos nacionales e internacionales. Así mismo hemos hecho notar la estrecha relación que existe entre la escuela y la EDH y como esta se encuentra 
traspasada por una serie de conflictos que generan tensiones entre ambas, las cuales pueden ser servir para consolidar o retrasar la implementación de los procesos pedagógicos.

Discurrimos que el Discurso Crítico de la Educación en Derechos Humanos(DCEDH) como el aporte que los profesores pueden y deben realizar para una (EDH) que promueva un carácter libertario entre las comunidades educativas y que permita superar la crisis de sentido que este discurso tiene en la actualidad; consideramos además que la tarea del (DCEDH) no solo es proporcionar una mirada desde debajo de los Derechos Humanos, en la cual los participantes de la experiencia educativa puedan vivir el potencial emancipatorio y de exigibilidad que ellos tienen, con el fin de hacer que el Estado cumpla con obligaciones que ha adquirido y que no ha cumplido para con su población; es decir que no solo deben ser concebidos como una suerte de re organizador del pacto social entre el Estado y los ciudadanos o como la manera de entablar diálogos entre las autoridades y los miembros de la sociedad. Sino que este discurso debe proponer una renovada de los fundamentos filosóficos sobre los cuales descansan los Derechos Humanos. 


\section{3- La Construcción del Discurso de los Profesores en la Educación en Derechos Humanos,} Debates y Controversias en el Magazín Aula Urbana y la Revista Educación y Cultura

\section{4- 2015}

El presente capitulo pretende mostrar cuales han sido los discursos elaborados por los profesores frente a la EDH, que tipo de posturas intelectuales se han desatado frente a su enseñanza y cuáles son las principales tensiones que subyacen a la construcción del mencionado discurso. Para efectos de una mayor comprensión del capítulo consideramos pertinente dividirlo en tres apartados; en el primero presentamos las disertaciones que los profesores han elaborado frente a la EDH, en el segundo los enfoques que se asumen frente a la EDH y en el tercero damos cuenta de las tensiones que se desarrollan en torno a la EDH.

\section{1- Discursos:}

Desde mediados del siglo XX, con la aparición de la Organización de las Naciones Unidas y el desarrollo de la declaración Universal de los Derechos Humanos, se le dio especial relevancia a la educación como herramienta preponderante para difundir una cultura alrededor de la defensa y promoción de los Derechos Humanos en todo el mundo. Sin embargo fue en el decenio de los noventas cuando se le concedió más fuerza a la EDH; producto del triunfo de las ideas liberales y su correlato del modelo capitalista de producción, con la crisis de los sistemas socialistas, el derrumbe de la Unión Soviética y las ideas de un mundo en el que ya no cabía pensar en opciones diversas de desarrollo para las sociedades. Las tensiones entre el capitalismo y el socialismo en América Latina se expresaron en acontecimientos como la revolución cubana, la llegada de Salvador Allende a la presidencia en Chile y su posterior derrocamiento por parte de la derecha chilena, el surgimiento de guerrillas de tendencia izquierdista en diversos lugares 
del sub-continente; la implantación de gobiernos de derecha en el cono sur (Argentina, Chile, Uruguay y Paraguay) una especie de sellamiento ideológico y el marginamiento del poder a opciones políticas diferentes a las tradicionales en Colombia vía Frente Nacional. Desde la segunda mitad del decenio de los ochentas los diferentes gobiernos de derecha en América Latina llegaron a su fin y muchas organizaciones sociales asumieron la defensa de la democracia y la denuncia de los abusos de poder y las violaciones a los Derechos Humanos por parte de los regímenes; a través de programas de EDH como una de sus herramientas privilegiadas, junto con la denuncia frente a los organismos defensores de los Derechos Humanos; para dar a conocer las situación que se vivía en cada uno de sus países y proponer salidas por la vía de la democracia a la crisis generalizada en la región; fue así como en Colombia organizaciones de la sociedad civil propusieron distintas acciones de reconocimiento de los actos de paz que se proponían en las comunidades en espacios como la semana por la paz que fue concebida por organizaciones religiosas y de base; así mismo el Estado colombiano impulso en 1988 una iniciativa en los colegios públicos conocida como "por una pedagogía de los Derechos Humanos” que fue el primer intento de llevar el asunto de los Derechos Humanos a las aulas de clase en el sistema formal de educación.

Los profesores colombianos han tenido distintas razones como la violencia política y social, la vulneración de sus propios derechos, su acercamiento a los problemas que a diario viven sus educandos y en general las comunidades con las cuales trabajan y la estructura rígida y autoritaria con la cual se ha desarrollado la escuela en Colombia, un contacto constante con la problemática de los Derechos Humanos y han perfilado reflexiones que pretenden no solo conseguir el cabal cumplimiento de los mismos por parte del Estado, sino que han elaborado discursos pedagógicos, tendientes a impactar a niños, niñas y jóvenes de la comunidad educativa 
en el conocimiento, la práctica, la defensa y la prevención de la vulneración de los Derechos Humanos; utilizando distintos referentes teóricos y haciendo énfasis en cuestiones cognitivas, valorativas o procedimentales y con propósitos diversos.

El discurso sobre la EDH ha ido evolucionando de acuerdo a los problemas que se consideren fundamentales en el momento, a los supuestos teóricos con los cuales se trabaje y al desarrollo político de la sociedad. Es así como desde finales de los ochentas comenzó a considerarse como un problema fundamental por parte del Estado la inclusión de los Derechos Humanos en la educación pública colombiana; la reacción de los educadores quedo plasmada en la revista Educación y Cultura de ese año en estos términos;

El gobierno nacional, a través de la consejería para los Derechos Humanos ha tomado la iniciativa de convertir los Derechos Humanos en tema prioritario de la escuela bajo la modalidad de una campaña o para ser más exactos "Una semana de los Derechos Humanos" y su correspondiente cartilla" (Educación y Cultura, 1988, N.16.P 3).

Desde esos días consideraban los profesores que este tipo de acciones poco y nada impactarían en la cultura de la escuela ya que eran acciones aisladas que no permitían dejar una huella en la escuela.

El tema de la $\mathrm{EDH}$, tiene un profundo significado en relación con la evolución de la pedagogía y las prácticas educativas que se han dado en nuestro país y con el papel que han tenido que asumir los profesores, en momentos en los cuales la negación y violación de estos les ha exigido plantear posiciones diáfanas en su doble condición de ciudadanos y educadores. En este sentido a finales del decenio de los ochentas, cuando por diversas razones (políticas, económicas, sociales y demás) comenzó a considerarse como un tema fundamental para el 
Estado colombiano y se emprendieron campañas (como la de mayo de 1988) tendientes a introducir el tema en las escuelas públicas del país como el escenario para su promoción y desarrollo, los profesores elaboraron un discurso de la EDH, el cual tenía como elementos principales; por un lado los reparos a las políticas que al respecto se impulsaban desde el Estado y por otro la denuncia de un modelo escolar autoritario y deshumanizado, el cual consideraban los educadores conservaba el país.

La crítica externa e interna que plantearon los educadores en su discurso sobre la EDH consideraba que era urgente que el gobierno propusiera cambios de fondo en la estructura y funciones del Estado, en los cuales se hiciera hincapié en la participación ciudadana para la toma de decisiones (económicas, políticas y jurídicas) que generaran cambios profundos en la sociedad y se promovieran los Derechos Humanos como el fundamento del pacto social entre los ciudadanos y el Estado.

En cuanto a la crítica interna se propuso como centro de la discusión el modelo educativo autoritario, que poseía una estructura de poder unipersonal en la cual los educandos no poseían espacios para el debate de sus ideas y la trasformación de la realidad; siendo la figura profesor una productora de verdades; desde esta perspectiva los educadores consideraban que:

Si pretendemos contribuir a la creación de una sociedad más justa e igualitaria, donde reine la paz con justicia social, tendremos que apoyar los agentes que puedan transformar la escuela, para que sea ella el laboratorio natural del hombre nuevo, de la sociedad nueva (Zafra, D.1988, N, 16, P.33). 
Para ello ponen de manifiesto que se requiere una democratización de la escuela, creando canales de participación en los proyectos educativos en los cuales se encuentren representados los miembros de las comunidades educativas.

El discurso que los profesores construyeron en torno a la EDH a finales del decenio de los ochentas, considero dos estrategias principales a la hora de hora de realizar la labor pedagógica; de un lado se apeló a la lectura y comentario de textos como la Declaración Universal de los Derechos Humanos y la Declaración de los Derechos del Niño, sin hacer mucho esfuerzo para comprender de manera analítica la vulneración de los mismos en el contexto colombiano. De otro lado se acudió a trabajar desde los espacios formalizados al interior del currículo como lo eran las cátedras (Bolivariana y de democracia) y la asignatura de Ciencias Sociales; en los cuales se privilegió el conocimiento memorístico y formal de los Derechos Humanos ya que en ellos se realizaban "exposiciones por medio de carteleras y resúmenes de lo que los educandos comprendían de cada uno de los derechos" (Romero, A.1988.N.16.P11) sin realizar trabajos contextuales en los que se analizaran estos derechos desde la realidad adyacente.

Por otra parte se desplegó una estrategia para el trabajo por parte de los profesores en la cual no se tocaba el tema de manera directa, sino que mediante temáticas relacionadas con los Derechos Humanos, como lo son la educación en democracia y valores, la enseñanza de la paz y convivencia; se abordaba tangencialmente en tópico de los derechos por parte del educador en el aula de clase. Esta obedecía a la lectura de contexto que hacían algunos pedagogos según la cual, trabajar el tema de manera directa podía traerles consecuencias para la seguridad tanto personal como familiar

Para el decenio de los noventas el discurso sobre la EDH, elaborado por los profesores colombianos tomo ciertos matices relevante debido a una serie de hechos que generaron mayores 
niveles de conciencia frente al trabajo que deberían hacer en lo correspondiente con una EDH al interior del movimiento profesor; tales acontecimientos tienen que ver con la profesionalización de la carrera profesor, la expedición de la Constitución Política de 1991 que inauguro unas renovadas relaciones de la sociedad civil con el Estado y la consolidación de las reivindicaciones del movimiento pedagógico encabezado por la Federación Colombiana de Educadores (FECODE) y expresado en la expedición de una ley general de educación (ley 115) que recogía por una parte, algunas de las reformas propuestas en la Constitución al ámbito de la escuela y por otra algunas de las máximas del movimiento magisterial en lo que tiene que ver con la transformación definitiva de las relaciones entre los diferentes miembros de las comunidades educativas haciendo de ellas u espacio de debate sobre los propósitos más elevados que debe perseguir la educación teniendo como telón de fondo el respeto por el otro, la dignidad humana, la democracia y los Derechos Humanos.

En el discurso construido por los profesores frente a la EDH, resaltara desde entonces un lenguaje renovado en el cual frases como gobierno escolar adquieren una enorme importancia debido a la posibilidad de concebir una cultura de participación democrática; en el cual la experiencia de los educandos se prioriza como material fundamental con miras al proceso de enseñanza aprendizaje; en donde valores como la libertad, la igualdad, la equidad, la solidaridad y el reconocimiento de la diferencia se consideraran el centro mismo de la enseñanza; en el que se concibe que se debe partir del reconocimiento de la dignidad humana como el fundamento de las relaciones humanas; en donde se propone que la educación debe ser necesariamente un proceso transversal, con el fin de que los educandos perciban la interdependencia (cognitivovalorativo) del conocimiento que ha desarrollado la humanidad y en el cual temas como la 
biodiversidad, la educación ambiental, el maltrato a los animales, la educación sexual y la memoria histórica hacen parte del currículo escolar.

Jenny Nieto (2010), en el mismo sentido considera que los profesores en sus discursos certifican que el derecho a la educación pasa por hacer de ella un espacio de calidad en el cual se garanticen los Derechos Humanos. Sin embargo este cambio en el lenguaje no quiere decir que la estructura autoritaria y patriarcal sobre la cual descansa el sistema educativo haya sido vencida. Lo que sucede es más, el reconocimiento de algunos cambios necesarios para acomodar el aparato escolar a los tiempos contemporáneos y las exigencias que los organismos internacionales hacen al Estado, para certificar sus avances en la protección de los Derechos Humanos en la sociedad.

Para Cardona, L (11997) en el discurso se considera que los Derechos Humanos se deben constituir en los estructurantes de las relaciones que se establecen en la escuela, entre pares, así como entre los demás miembros de la comunidad educativa (profesores, directivos, padres de familia y otros) así mismo que estos se encuentren en el centro del proceso de conocimiento; en tanto expresión del autoconocimiento humano, de las relaciones con el entorno y de la valoración que se tienen de aquel.

Según Osorio, J (1997) la plena realización de la vida humana se debe considerar el principio básico de todo proyecto educativo que pretenda colocar en el centro del debate pedagógico al ser humano y en este caso es la EDH, la herramienta fundamental ya que considera como constitutivo de sí misma, la autorrealización, la autonomía y la solidaridad fundamentos de una transformación de la escuela y de sus relaciones y estructuras verticales y autoritarias de poder. 
En lo que tiene que ver con las estrategias privilegiadas por el discurso que los educadores han creado sobre la EDH, estos consideran fundamental; el diseño de ambientes de aprendizaje a partir de la realidad social en los cuales se limita por un lado el poder de intervención y control por parte del profesor y por otra se privilegia el ingreso a las aulas de la vida cotidiana (algo que había sido relegado a experiencias puntuales y de innovación) es decir que se considera la vida cotidiana de los educandos como materia prima en el proceso de conocimiento y como mediadora de las relaciones sociales que se establecen en el ámbito escolar. Así mismo se considera que hay que generar espacios en los cuales se promueva la autonomía personal de los estudiantes, la argumentación como principio efectivo para la resolución de los conflictos de manera no violenta entre los miembros de la comunidad educativa y en diferentes escenarios de la vida cotidiana y se generen los mecanismos idóneos que permitan superar la discriminación y la exclusión al interior de las instituciones educativas, que en muchos casos sirven como reproductoras de esos y otros problemas. Para los educadores una de las estrategias que se debe implementar tiene que ver con que "las políticas y las prácticas y relaciones pedagógicas en la vida escolar se deben orientar a la superación de la desigualdad social y la inequidad" (Pabón, R. 2012, N 87, p.3).

Osorio, J. considera que originan diversos trabajos y metodologías en las cuales se promueven el respeto por el otro, la diversidad (cultural, étnica y de género) y la capacidad de reciprocidad frente a los demás; todo ello para resaltar la tolerancia como principio y fundamento de las relaciones humanas. En síntesis se concibe el acto educativo desde un enfoque de derechos el cual "ha venido construyéndose de manera progresiva con aportes 'provenientes de diferentes sectores y con matices conceptuales y políticos" (Pulido, O. 2013, N 88, p.11). Se estimula la inclusión de la memoria histórica como herramienta que privilegie el conocimiento de los 
acontecimientos muchas veces traumáticos por los cuales han pasado los individuos y las sociedades; así como la posibilidad de sanación mediante la comprensión de los hechos acaecidos y finalmente la posibilidad de no repetición por el estudio y el constante recordatorio de los hechos sucedidos.

También se plantea como estrategia la educación ciudadana; entendida esta no solo como cualidad intrínseca que poseen los ciudadanos modernos, sino, más bien como proceso ético mediante el cual se promueven los valores propios de la democracia ; es decir la participación política, la reciprocidad y el sentido crítico que permiten un mayor entendimiento y convivencia pacífica entre los ciudadanos.

Al comenzar un nuevo siglo (XXI) el discurso manejado por los educadores en torno a la EDH, esta pletórico de viejos y nuevos temas para consolidar una propuesta coherente que permita pensar un cambio social gestado desde las aulas de clase; entre los temas que se repiten se encuentra la defensa de la educación pública como derecho fundamental, la protección del trabajo de los educadores en tanto trabajadores de la cultura, el amparo de los derechos del magisterio en cuanto gremio asociándolos al cabal desarrollo del derecho a la educación, la gratuidad y la calidad de la educación en lo que tienen que ver con la dignidad del ser humano expresada en el derecho a la educación. Así mismo toman fuerza temas como la etno-educación, la educación para la sexualidad, la educación para la democracia, las temáticas de convivencia y valores y la educación en el marco del post conflicto.

Para los profesores el derecho a la educación además de ser considerado como fundamental es "esencial para la construcción de una vida digna" (Avellaneda, L.C.2003, N 64, P 15). Ya que su adecuado desarrollo e implementación permitiría que los educandos accedieran a diversos bienes que se encuentran en la sociedad; en este sentido consideran que la EDH, no es 
exclusivamente un acto académico-intelectual, sino, que demás es cultural y moral y que en él se involucran los postulados más profundos que posee el Estado y los principios más elevados ostenta la sociedad y es en este sentido que el DEH, lo considera como un derecho radical en el sentido que "sin él no es posible la existencia de la sociedad y el ejercicio de los demás Derechos Humanos. Esto es, el derecho a la educación fundamenta la existencia de toda civilización” (Avellaneda, L.C.2003, N 64, p.17).

Para los educadores la EDH, debe ser considerada además, como una herramienta de denuncia ya que sienten violentados sus Derechos Humanos por parte de miembros del Estado, quienes estigmatizan el derecho a la protesta a propósito dicen "existe una tendencia a que la protesta sea vista como polarizada y los líderes y activistas de la misma seamos señalados, tanto por el Estado como por las fuerzas paramilitares como subversivos" (Cuello, R.2011.N 91, p. 69). En este sentido los miembros del magisterio han tenido que afrontar desplazamientos forzados, homicidios, detenciones arbitrarias y otros delitos que los conduce a considerar que una de sus que la defensa de su actividad e incluso sus vidas pasa la denuncia permanente en las aulas educando a los jóvenes y a sus padres en la defensa de los Derechos Humanos de todos los miembros de la sociedad.

De otra parte el discurso de los educadores con respecto a la EDH, considera la formación para la democracia como ingrediente fundamental a la hora de fomentar una cultura del respeto y practica de los Derechos Humanos; en este sentido propenden por crear una cultura política democrática que permita la participación de más sectores de la vida pública en la política y cambiar la mentalidad violenta con la cual se hace y se vive la política en Colombia, para ello consideran fundamental la construcción de una cultura escolar en la cual las relaciones de poder se establezcan de manera horizontal y permitan en desarrollo de formas de relacionarse 
democráticas entre los diferentes actores del proceso de enseñanza-aprendizaje; otra estrategia es la que propone Bayona, A.(1999) en la cual se concibe a la escuela en cuanto comunidad educativa con lo cual se lograría una mayor participación de la comunidad y la sociedad en todo el proceso educativo y finalmente impulsar la idea de pensar la educación como derecho radical, en tanto da sentido a los demás Derechos Humanos.

Para los profesores la EDH, debe tener en cuenta a los pueblos originales y las comunidades tradicionales y es en este sentido en que se plantea la necesidad de desarrollar la etno-educación como reflexión ontológica de los miembros de las comunidades (indígenas y afro descendientes) y no solo en cuanto derecho otorgado por la Constitución Política; es más una preocupación nacida del auto reconocimiento de los miembros de estas comunidades de sus particularidades y diferencias y como potenciarlas mediante la educación propia. Es así como consideran que "el topo de educación que responde a las realidades y necesidades de los individuos y pueblos indígenas y afro descendientes, no puede circunscribirse solo a la mirada negativa de la subalternización de estos sujetos...partiendo de su invisibilidad e inferioridad de carácter durante la colonia y la independencia” (Ramírez, A.2010, N 86, p. 23-24).

\section{2- Enfoques.}

En lo que tiene que ver con los enfoques que privilegian los educadores en su discurso sobre la EDH, consideramos que estos se pueden agrupar siguiendo la propuesta de Magendzo (2002) en la cual se distinguen cinco direcciones a la hora de pensar el trabajo en la EDH, de la siguiente manera: aquellos que ponen el acento en la conceptualización y la operacionalización de la propuesta; los que consideran que lo fundamental son los objetivos que pretenden alcanzar con el trabajo; otros que hacen hincapié en los valores que se deben conseguir mediante la tarea; los que creen que lo más importante está en el conocimiento, la metodología, la evaluación y el 
rol que juegan tanto los educandos como los educadores y finalmente los enfoques que consideran que el principio fundamental está en la pedagogía critica. Es necesario de antemano aclarar que en las practicas pedagógicas estos enfoque no se encuentran de manera diáfana ya que en la experiencia real generalmente se utiliza una mixtura d orientaciones y que solo para efectos investigativos tratamos de distinguir las practicas con el ánimo de mostrar rasgos particulares y generales que resaltan en cada una de ellas.

Una perspectiva manejada por los profesores a la hora de trabajar sobre la EDH; tiene que ver con poner en acento en la conceptualización y operacionalización de la propuesta a desarrollar; en este sentido los educadores consideran que las características que identifican a un currículo centrado en los Derechos Humanos tiene que ver con que este debe ser abierto y flexible, con el fin de que los profesores puedan adecuarlo a contextos y escenarios diversos; debe estar centrada en el desarrollo humano de los educandos considerándolo de manera integral (tanto cognitivamente como socio-afectivamente; debe ser problematizador de la realidad social; debe ser integrador tanto de las experiencias individuales como colectivas de las personas que participan; tiene que relacionar la teoría y la práctica, es decir que permita relacionar las experiencias personales con las colectivas y les proporcione un sentido desde las bases filosóficas, históricas y éticas de los Derechos Humanos; debe ser liberador en la medida en que permita que cada persona actué bajo su propia manera de entender las relaciones y considere el respeto de los otros y finalmente debe ser estructurante de las relaciones que se dan entre los distintos actores del proceso educativo (Cardona, L.1998, N 41,p. 4-6).

De otro lado existen propuestas para desarrollar valores sociales, tales como la ciudadanía entendida esta como un proceso de formación ético en el cual se fomenta la participación ciudadana como principio de la democracia, en este sentido proponen que la 
escuela "debe adoptar como principios organizadores el lenguaje ético, la formación valoral y el desarrollo de la capacidad autónoma de los sujetos si optan por participar responsablemente en la construcción de la ciudadanía democrática” (Osorio, J.1997, N 41, p.15).

Así mismo consideran que la EDH, debe fomentar la deliberación, la reciprocidad y el respeto a la diversidad, por medio de una mirada renovadora sobre la política y la ciudadanía; en este sentido los profesores proponen "la reconfiguración de las culturas políticas y la redefinición de una cultura política democrática, mediante textos-talleres que redefinan la formación política y ciudadana de los estudiantes” (Zuluaga, L.M. Peláez, P. Guerrero, V. \&Gaviria, Z. 2014, N 92, p.8). Por ello consideran que el objetivo principal debe ser una educación en valores que les permita a los estudiantes deliberar a partir de situaciones controversiales.

Los problemas éticos estudiados deben surgir de los cuestionamientos que los estudiantes propongan, así como sus soluciones; en este sentido consideran los profesores que por el afán de dar solución a los cuestionamientos planteados por los educandos, en muchas ocasiones el educador opta por proponer una respuesta a la contrariedad propuesta dejando de lado "las diferentes cosmovisiones que en torno a la realidad ha construido el alumno de forma significativa" (Manrique, M.M.1998.N.5.P.10) lo cual contribuiría a la negación del estudiante como legitimo otro y sería una insuficiencia de la EDH, puesto que esta vista desde los valores debe partir del principio aquellos no se enseñan, ni se aprenden, sino que se viven e incorporan a la vida diaria; por lo cual hay que planear la manera en que se agregaran a las conductas de los seres humanos.

El enfoque que considera que lo fundamental en la EDH, debe ser el aprendizaje, las metodologías, la evaluación y el rol que desempeñan tanto los educandos como los educadores se ve reflejado en la escrupulosa planeación que hacen de aspectos tales como los fundamentos 
filosóficos y científicos sobre los cuales descansa la propuesta, las características (económicas, sociales y culturales) de los estudiantes, las necesidades que se tienen al interior de la institución y a sus alrededores no solo en materia de convivencia, pero además sus potencialidades intereses y ritmos de aprendizaje; para concertar las metodologías que en general parten del contexto teniendo en cuenta la experiencia vivida por los educandos, sus familias y la comunidad y para insertarlas en dinámicas más amplias que permitan comprenderlas como parte de los procesos locales, regionales y nacionales y den sentido a esta experiencia permitiendo que transformen la realidad (Nieto, J.2010, N 75, p. 9).

Quienes defienden la idea de que lo central en la EDH, son los objetivos trazados para el desarrollo del trabajo, consideran que el punto central estriba en "empoderar a las personas para que asuman la responsabilidad de hacer reivindicar sus derechos mediante el uso de la argumentación y el dialogo" (Vázquez, O. 201. N 81, p.6). Consideran que la tarea de la EDH debe ser considerar escenarios en los cuales se pueda conseguir reclamar y disfrutar de los derechos por parte de los educandos y que allí estaría el principal reto de la escuela ya que esta por su naturaleza es autoritaria.

La EDH, debe promover como objetivo primordial el desarrollo pleno del derecho a la educación sin discriminación alguna como condición para lograr el pleno goce de los Derechos Humanos en la sociedad actual que sigue vulnerando los derechos a quienes más los necesitan es decir a las poblaciones más indefensas; es allí donde la EDH, debe proponer las estrategias capaces de revertir estas condiciones de inequidad, para con ello lograr un compromiso de los individuos para con el respeto y la práctica de los Derechos Humanos.

Desde una perspectiva holística los trabajos que se proponen desde la pedagogía crítica como enfoque primario consideran que la $\mathrm{EDH}$, no tiene que ver con introducir en el currículo 
una serie de contenidos que aborden los Derechos Humanos en uno o varios espacios académicos, en seminarios o acciones puntuales e individuales desconectadas de los acontecimientos reales que viven los educandos en sus contextos más inmediatos. Para quienes defienden este enfoque "los Derechos Humanos constituyen por si un ideología educativa que compromete la esencia misma del currículo tanto manifiesto como oculto y por consiguiente su incorporación exige un repensar del currículo" (Romero, A.1988.N, 16, p.7). Es en este sentido que consideran que es el currículo en cuanto conjunto de intenciones predeterminadas por una comunidad con el fin de intervenir en la cultura el que debe ser objeto de modificaciones teniendo en cuenta las particularidades y necesidades de cada una de las comunidades, es decir que hay que tener claro que tipo de persona es la que se quiere formar en lo intelectual, lo social, lo moral y lo ético y desde allí proponer los cambios que el plan de estudios requiere para conseguir la tarea que se plantea.

Hasta aquí hemos visto como se ha desarrollado el discurso de los profesores sobre la $\mathrm{EDH}$, en que han puesto especial interés y cuales consideran deben ser los principales caminos que deben trasegar los educadores que pretendan hacer énfasis en ella con miras a transformar

los ambientes escolares y a mejorar las condiciones de vida de los educandos, sus familias y la de los propios educadores.

\section{3- Tensiones}

Las principales tensiones que podemos analizar en el presente capitulo tienen que ver con dos temas principales; por un lado se encuentran todas aquellas que apelan directamente a los asuntos propiamente pedagógicos, mientras que las otras pasan por considerar las intenciones históricas, políticas y filosóficas que mueven a los profesores que se dedican a trabajar en pro de la EDH. 
La primera de ellas está planteada entre quienes consideran que la $\mathrm{EDH}$, tiene que ver con la adición de unos contenidos (Jurídicos, históricos, éticos, políticos y morales), unas didácticas, unas metodologías y una manera de evaluar, para uno o varias asignaturas ya existentes en el currículo; estos suponen que es una nueva carga que la sociedad en su conjunto le impone a la escuela, sin proporcionar los elementos estructurales (en términos de hacer o mejorar los espacios en los que estudiantes y profesores se educan, sin realizar el trabajo de crear las condiciones para que existan profesionales dedicados a educar en el tema, sin suficiente desarrollo en términos de metodologías para ello y en fin sin la infraestructura tanto humana como de servicios y recursos) que le permitan a las instituciones escolares asumirla de una manera positiva y aquellos que ven en la $\mathrm{EDH}$, una oportunidad que se le otorga a la escuela para cambiar la cultura escolar profundamente antidemocrática mediante la cual se han desarrollado las relaciones entre los diversos actores que confluyen en las instituciones escolares, para quienes apoyan esta posición la EDH, tendría que proponer cambios estructurales al interior del currículo, en las relaciones estudiante profesor, en la manera de conocer y en como valoramos unos tipos de conocimientos por sobre otros, en las relaciones de las comunidades con las escuelas y en fin en todas las maneras de relacionarse con el propósito de impactar en la vida diaria de los estudiantes y sus familias.

Otra tensión que se puede comprender es la que se manifiesta entre quienes piensan que lo más acertado seria concebir un espacio autónomo y propio para la EDH, al interior del currículo ya que esto garantizaría el perfeccionamiento de unos contenidos apropiados a dicha área del conocimiento, unas didácticas acordes y unas metodologías coherentes con los objetivos que se proponen conseguir; piensan que disfrutar de unos espacios y tiempos al interior del plan de estudios garantizaría mayores niveles de legitimidad a los procesos educativos y convendría 
que algo tan fundamental como la $\mathrm{EDH}$, debería estar claramente incluida en este. En contraste están los educadores que advierten en la curricularización de los Derechos Humanos un problema ya que le restaría posibilidades al trabajo creativo que se puede hacer desde las hendiduras que deja el currículo y que se pierden si se formalizan las intenciones pedagógicas en un plan de estudios, argumentan además que es en esos intersticios que deja el plan de estudios en donde es posible encajar la EDH para que puede impactar de manera más concreta y constante en la cultura escolar.

Por otra parte se encuentran las tensiones que dan cuenta de las finalidades políticas, filosóficas e históricas que conservan los educadores que pretenden ocuparse en EDH; entre estas encontramos la que se presenta entre los pedagogos que consideran que el principal objetivo de este tipo de educación debe ser intervenir en la cultura escolar y cambiar las relaciones de poder que subyacen a esta, fomentando la democracia y la autonomía en las decisiones que toman al interior de los planteles educativos y que afectan de manera directa la vida de los miembros de la comunidad educativa; contrasta con esta intensión la de aquellos que piensan que el discurso sobre los Derechos Humanos edificado por las estructuras de poder aspira legitimar la intervención de los países poderosos sobre aquellos que no se adhieren a las políticas del dominio y por tanto la EDH legitimaria las arbitrariedades y desproporciones de autoridad, solo por el hecho de legitimar una forma de entender la vida dada en una cultura determinada, para todos los seres humanos.

Una tensión diferente encontramos entre quienes proyectan la idea de que la EDH debe en todo caso actuar siguiendo los parámetros y definiciones que el derecho internacional de los Derechos Humanos ha perfeccionado ya que de lo que se trata es de hacer más asequible este discurso a los educandos y no de proponer cambios estructurales en el mismo, para ellos los 
profesores deben hacer énfasis en cuestiones estructurales de esta teoría como serian la dignidad humana, el ser humanos como sujeto de derechos, la universalidad de los derechos por considerarse estos como connaturales a la especie y no a una cultura. Por el otro lado encontramos a quienes ven en la EDH, una oportunidad para hacer una mirada crítica de los principios fundamentales sobre los cuales descansa la teoría, en este caso se pretende hacer de los Derechos Humanos el espacio de crítica del papel del Estado en la solución de los problemas que afectan la vida diaria de los seres humanos, la democracia como sistema privilegiado por las sociedades para ejercer la participación de la mayor parte de ciudadanos en las decisiones que se toman y que afectan en trasegar humano y el papel de la ciudadanía como motor de los cambios que necesita el mundo para continuar y mantenerse.

Finalmente tenemos la tensión entre quienes proponen que el objetivo fundamental de la EDH, debe ser de promulgadora del contenido jurídico de los Derechos Humanos, informando a los miembros de la comunidad educativa que son, como se ejercen y que se debe hacer cuando se sienta que se están vulnerando los derechos de las personas y quienes plantean que el asunto fundamental se debe entender en términos morales y éticos y en consecuencia es desde el análisis de las decisiones que se toman en la vida diaria, desde donde hay que educar, mostrando las consecuencias prácticas de las determinaciones que se toman y comprendiendo la interconexión que existe entre todas las sociedades y la corresponsabilidad que cada miembro de una comunidad debe tener para con los demás. 


\section{4- Conclusiones.}

El itinerario del estudio formulado consideraba que a partir del análisis reflexivo de dos series de documentos (aula Urbana y Educación y Cultura) se pudiera dar cuenta del discurso elaborado por los profesores, en lo que hace relación con la EDH; recapacitando en ello propusimos una mirada según la cual diéramos cuenta de las discusiones que se dan al respecto entre los educadores y que nos permitiera dar cuenta de ellas en las revistas seleccionadas.

Siguiendo esta trayectoria se analizó la manera en que surgió la discusión sobre la EDH, tanto en los acuerdos internacionales que han sido suscritos por Colombia para el cumplimiento y la práctica de los Derechos Humanos; como las experiencias que el EDH se han perfeccionado en la base a partir de este cruce consideramos que los descubrimientos más relevantes tienen que ver con el hecho de que durante el decenio de los setentas del siglo pasado, empezó a desarrollarse en el país la EDH, debido a la situación de constante amenaza para la vida de quienes defendían los Derechos Humanos; lo principal por aquella época era posicionar el tema del respeto y práctica de la libertad como fundamento de los derechos y el escenario privilegiado fue la educación no formal; organizaciones de base, sindicatos, grupos de víctimas y los grupos religiosos que tenían trabajo barrial de alfabetización con adultos iniciaron el recorrido de la EDH en nuestro país.

Este mismo itinerario nos condijo a mostrar como la EDH, se presenta como un derecho humano autónomo y por tanto separado del derecho a la educación, lo cual implico comprender la manera en la que este se hace realidad en los entornos escolares, mediante el análisis del contenido de los discursos elaborados por los profesores, ya que el ellos se pueden examinar los 
dogmas de los educadores frente al tema, como lo trabajan en sus aulas y que tipo de fundamentación filosófica es la que han elaborado o recogido.

La metodología que se ha privilegiado desde las primeras experiencias y hasta la actualidad tiene que ver con la pedagogía crítica y la educación para la libertad; según la cual se parte de la realidad circundante en la cual se encuentran inmersos los participantes haciendo una lectura de contexto para intervenir y transformar la realidad; comprendiendo en todo momento que el conocimiento se construye desde la realidad y es un producto de aquella, por lo que nadie lo posee de antemano. Así mismo se promueven procesos democráticos en los cuales se comprende que la transformación de la realidad social se consigue mediante el concurso de toda la comunidad y que es mediante el conocimiento profundo de la misma como se trasmuta.

Durante los ochentas se construyeron innumerables experiencias en la educación no formal frente a la EDH en temas específicos como la defensa de los derechos de los trabajadores, de los grupos étnicos de las mujeres y de las minorías sexuales, las cuales contribuyeron a poner distintas temáticas de la, EDH, en el escenario local y nacional. A un así en trabajo en el sector formal de la educación fue esporádico y aislado por que el tema representaba un peligro para los educadores que lo trabajaban en las comunidades afectadas por el conflicto interno del país y los esfuerzos fueron aislados y en todo caso no muy difundidos por los profesores ni el Estado.

Fue durante el decenio de los noventas cuando la EDH, incursiono con fuerza en el contexto de la educación formal de la escuela colombiana; debido principalmente a la expedición de la Constitución Política de 1991, que amplio la participación política y la democracia a sectores de la sociedad que tradicionalmente habían sido marginados y modernizo el Estado y sus instituciones; fue en este escenario en el cual se hizo hincapié en los Derechos Humanos y se 
privilegió a la institución educativa como espacio ideal para que se diera una transformación de la cultura patriarcal y autoritaria mediante la cual se había desarrollado el país.

En el derecho internacional de los Derechos Humanos se ha contemplado desde mediados del siglo pasado como uno de sus frentes de trabajo la EDH, como herramienta para la trasmisión e interiorización de los principios que considera fundamentales para una sana convivencia de los miembros de la familia humana; desde esta perspectiva todos los tratados y acuerdos que tienen un carácter vinculante la par los miembros de las Naciones Unidas, han tenido en cuenta la pedagogía como estrategia para ganar legitimidad frente a la sociedad. A medida que se fue ampliando el tema y por la trascendencia que este ha tenido, fue adquiriendo sentido considerar que la EDH, es un derecho autónomo y separado del derecho a la educación ya que este permite entender y disfrutar de los demás Derechos Humanos.

Como parte de sus compromisos con los tratados internacionales Colombia ha venido desde el decenio de los noventas del siglo pasado, incorporando a su legislación las leyes que garanticen la promoción y practica de los Derechos Humanos como política pública. En este sentido se ha hecho un trabajo desde diversas instituciones (defensoría del Pueblo, ministerio de educación, fiscalía general de la nación, procuraduría y la vice presidencia entre otras) para promover el respeto de los mismos por parte de los servidores públicos y se ha propuesto un plan nacional de educación en Derechos Humanos, como estrategia para masificar el contenido y transformar la cultura autoritaria por un escenario de diálogo y concertación frente a la EDH, al interior de la sociedad, en este sentido la escuela juega un papel preponderante ya que es el lugar en el cual se preparan los jóvenes para promover y desarrollar los cambios estructurales que en esta materia requiere el país. 
Por otro lado resalta la fundamentación teórica, frente a la crítica de la EDH y la construcción de una propuesta que considere que toda $\mathrm{EDH}$, debe considerarse desde un enfoque crítico, en el sentido de reflexionar acerca de los fundamentos filosóficos sobre los que descansa la EDH. Así consideramos que los educadores han construido sus discursos alrededor de unos principios teóricos tradicionales frente a los Derechos Humanos en los cuales no se ponen en entre dicho las ideas sobre las cuales descansan. No se han propuesto alternativas a una concepción según la cual es la democracia el sistema de representación más adecuado sobre el cual se pueden desarrollar los Derechos Humanos; no se realizan críticas a la concepción universalista de los derechos que niega de tajo la posibilidad del dialogo de las civilizaciones, no se cuestiona el principio del sujeto de derechos o la dignidad humana como fundamentos de un individualismo y contradictorio de los derechos como representaciones de las aspiraciones colectivas que tienen las comunidades para un mejor vivir de todos sus miembros.

El análisis del discurso que hemos hecho desde la lectura transversal de las dos revistas nos ha permitido comprender que la EDH, sigue siendo un nicho importante para la transformación de la realidad social de las comunidades, puesto que no se ha explorado a fondo la exigibilidad de algunos Derechos Humanos que permitirían a las instituciones educativas contribuir de manera radical en la construcción y consolidación de una sociedad más justa y equitativa.

Es necesario considerar la fuerza trasgresora que tiene una $\mathrm{EDH}$, que se conciba a si misma desde un enfoque crítico, no solo por su metodología de trabajo e intervención, sino que se piense como alternativa de las bases filosóficas y los principios sobre los cuales descansa la teoría de los Derechos Humanos; es obligatorio que los profesores las propuestas que al respecto 
se están elaborando desde los países periféricos o emergentes y que aportan en una concepción más extensa e incluyente de los Derechos Humanos.

Las primeras experiencias en la EDH, desde el sector formal de la educación consideraban que el problema principal en la vulneración de los Derechos Humanos pasaba por el desconocimiento de los mismos por parte de los funcionarios del Estado así como la ciudadanía en general, por lo que se conjeturó que mejorar en el cuidado la práctica y la promoción de estos derechos, se conseguiría si los funcionarios públicos y los miembros de la sociedad civil los conocieran a profundidad; la escuela entonces debería asumir el papel de dar a conocer el contenido de los Derechos Humanos y no de hacerles una crítica profunda a los principios filosóficos, históricos y políticos sobre los cuales descansa esta teoría, todo se resumió a un problema del derecho. Esta concepción ha ido transformándose de manera tal que hoy existen voces que consideran que la cuestión tiene que ver más con un problema ético y moral y su principal argumento es que hoy la mayoría de las personas conocen los derechos y a pesar de ello continua existiendo una violación elevada de los mismos, los niveles de violencia no bajan y la cultura antidemocrática y autoritaria sigue siendo el signo característico de nuestra sociedad.

El impacto que presenta la investigación tiene que ver con la posibilidad de generar espacios de reflexión y consolidación en la ampliación de derechos entre los educandos de nuestra sociedad desde los escenarios educativos; privilegiando en ellos la participación de los jóvenes en la vida pública y en la construcción de una cultura en la cual la palabra, la reflexión y el buen trato se encuentren en el centro de todos los procesos.

Otro escenario en el que podríamos medir la huella que esta investigación puede dejar, sería la escuela como espacio en el cual se generan disputas incesantes por el poder y el control de los saberes entre la academia y los saberes tradicionales de las comunidades; en este orden de 
ideas la Educación en Derechos Humanos (EDH) permitiría comprender la importancia que tienen los conocimientos tradicionales con los cuales asisten a ella los educandos e intentar negociar entre lo que la academia propone y lo que las tradiciones de los hogares conciben como fundamental para los más jóvenes. Es decir se podría convertir en un puente que una las diversas formas de conocimientos que a diario se dan cita en la escuela y que en la mayoría de casos se jerarquizan teniendo como racero la ciencia.

Consideramos que otro aspecto que debemos resaltar en lo que tiene que ver con el impacto de nuestra investigación tiene que ver con la enorme fuerza transformadora que la Educación en Derechos Humanos (EDH) posee en lo que tiene que ver con las transformación de una cultura patriarcal y antidemocrática, desde la cual se han concebido los escenarios escolares tradicionales y espíritu liberador y democratizador que potencialmente tendrían propuestas como la educación en derechos para una sociedad como la nuestra, en la materialización en la vida cotidiana de una cultura de paz basada en el respeto y la práctica de los Derechos Humanos.

Un escenario en el cual este trabajo puede generar mayor impacto puede ser en la construcción, desarrollo y consolidación de políticas públicas que pretendan ahondar en la Educación en Derechos Humanos (EDH) en tanto derecho fundamental, tan importante como las ciencias o los idiomas o en general como todos los conocimientos que consideramos fundamentales para que un joven pueda tener un proyecto de vida digno que lo lleve a ser feliz. Desde esta perspectiva vemos como asunto fundamental la participación de los profesores en la elaboración de las políticas públicas que tengan como fondo en trabajo en el diseño de los instrumentos de intervención de la escuela con la idea de cambiar la cultura de esta mediante la Educación en Derechos Humanos (EDH). 
Es necesario considerar a la EDH, como un discurso crítico que busca la libertad y considera las potencialidades humanas; en tanto discurso crítico un puede cazarse con una única manera de razonar ya que eso negaría la enorme fuerza que posee como transformadora d las realidades a las cuales se enfrentan los educandos. En cuanto practica liberadora se requiere de una enorme voluntad de los educadores para considerar que todo conocimiento debe conducir a la creación de un pensamiento autónomo entre los educandos y que debe conllevar a la libertad no solo personal pero social.

El estudio planteado abre la posibilidad para continuar trabajando en los discursos alrededor de la EDH, planteándonos inquietudes tales como ¿Qué tipo de intereses políticos, culturales y sociales existen en la configuración del discurso sobre la EDH? Lo cual nos permitiría comprender de manera más profunda las condiciones que subyacen a la consolidación de los desarrollos pedagógicos alrededor del tema planteado.

Un camino que apenas fue tangencialmente tocado en este estudio tiene que ver con la existencia o no de un Discurso Crítico sobre la Educación en Derechos Humanos (DCEDH) que propenda por entender de manera radicalmente diferente los principios filosóficos y políticos sobre los cuales se afirma la teoría de los Derechos Humanos en la cultura Occidental; esto con el fin de hacer más incluyente este discurso y acogido por mas sociedades. Es necesario proponer alternativas para entender la universalidad de los Derechos Humanos, incluir miradas diversas sobre el desarrollo del sujeto de derechos columna vertebral de la propuesta, hay que discutir que es y cuál es el alcance de la dignidad humana y discernir si es la democracia el único sistema de representación político capaz de hacer cumplir los Derechos Humanos entre las sociedades. Consideramos que todos esos temas podrían ser tratados desde las instituciones educativas en perspectiva de un DCEDH. 


\section{Libros}

\section{Referencias Bibliográficas.}

Bourdieu, P. (2da edición) (1996). La Reproducción: Elementos para una Teoría del Sistema de Enseñanza. México D.F, México: Fontanamara.

De Sousa, B. (1998). De la Mano de Alicia: Lo Social y lo Político en la Postmodernidad. Bogotá, Colombia: Siglo del Hombre editores Uniandes

Foucault, M. (2003). Vigilar y Castigar: Nacimiento de la Prisión. Buenos Aires, Argentina: Siglo veintiuno editores.

Menke, CH. Y Pollmann, A. (2010). Filosofía de los Derechos Humanos. Barcelona, España: Herder.

Pogge, T. (2005) La pobreza en el Mundo y los Derechos Humanos. Barcelona, España: Paidós.

Instituto Interamericano de Derechos Humanos (1994) Educación en Derechos Humanos: Texto Autoformativo. San José, Costa Rica. IIDH.

Universidad Jorge Tadeo Lozano (2012) Identidades, enfoque Diferencial y Construcción de Paz. Bogotá, Colombia: FOS-Colombia

\section{Artículos en Revistas}

Andreu, J. (2001 Diciembre). Andalucía. Las Técnicas de Análisis de Contenido: Una Revisión Actualizada. Centro de Estudios Andaluces, 1-34.

Arana, I. Rapacci, M. (2013). La educación propia una realidad oculta de resistencia Educativa y cultural de los pueblos. Entretejidos de la educación popular en Colombia. Ediciones desde abajo.81-98.

Avellaneda, L. C. (2003). La educación como derecho Fundamental. En: Educación y Cultura, 64, 15-20.

Bayona, A. (1999.Diciembre). Bogotá. Hacia una Cultura Escolar Democrática. Educación y Cultura, (50), 95-98.

Bolaños G. y Tatay L. (2013). La educación propia una realidad oculta de resistencia Educativa y cultural de los pueblos. Entretejidos de la educación popular en Colombia. Ediciones desde abajo, (6), 5-81.

Cardona, L. (1997. Marzo). Aportes para el diseño de un Currículo de Derechos Humanos. Educación y Cultura, (41), 4-11. 
Cuello, R. (2011. Julio). Los Derechos Humanos y su Relación con la Educación y los Educadores: ¿Por qué Razones Asesinan a los Maestros? Educación y Cultura, (91), 6771.

Delpiano, A. Madgenzo, A. (1988. Octubre). La Escuela Formal, el Currículum Escolar y los Derechos Humanos. Educación y Cultura, (16), 5-8.

Educación y Cultura (1988. Octubre). Educación y Derechos Humanos Editorial. Educación y Cultura, (16), 2-3.

Espinel, O.O. (2010 Julio/Diciembre). Pedagogías Críticas y educación en Derechos Humanos: Una Mirada desde Escenarios escolares y no Escolares. Nodos y Nudos, (29), 42-50.

Espinel, O.O (2013). Bogotá. Educación en Derechos Humanos: esbozo de una Lectura Biopolítica. Revista Colombiana de Educación, (65), 101-121.

Leal, A. (2009. Mayo). Introducción al Discurso Pedagógico. Revista Horizonte Educacional, (14), 51-63.

Manrique, M.M. (1998. Marzo/Abril). Los Valores Expresión de Armonía Social. Aula Urbana, (5), 10 .

Martínez. V. (2007. Septiembre/Diciembre). Diversos Condicionamientos del Fracaso Escolar en Secundaria. Revista Iberoamericana de Educación, (51), 67-85.

Mestre, J.V. (2005. Enero). Legitimación Filosófica de los Derechos Humanos. A parte Rey. Revista de Filosofía, (37), 1-5.

Mujica, R.M. (2000. Julio/Diciembre). ¿Qué es Educar en Derechos Humanos? DEHUIDELA. Revista de Filosofía, (26), 21-36.

Nieto, J. (2010. Enero). Integración Curricular de los Derechos Humanos. Aula Urbana, (75), 89.

Osorio, J. (1997. Mayo). La Educación en Derechos Humanos: Transversalidad y Proyectos Educativos. Educación y Cultura, (41), 12-18.

Pabón, R. (2012). Diversidad, Inclusión y Derecho a la Educación Para Todos y Todas. Aula Urbana, (87), 3-4.

Pulido, O. (2013). El enfoque de Derechos en Educación. Aula Urbana, (88), 11.

Piñuela, J.L. (2002) Epistemología, Metodología y técnicas del Análisis de Contenido. Estudios Sociolingüísticos, (3), 1-42.

Ramírez, A. (2010. Marzo). ¿Qué tipo de educación indígena y afro descendiente se requiere en Colombia? Educación y Cultura, (86), 23-27.

Restrepo, M. (2008). Apuntes para una Reflexión sobre Pedagogía de los Derechos Humanos en Colombia. Monografías ONU, 104-133. 
Rodríguez, W.G. (2012). El Discurso Pedagógico. Mecanismos de poder y Control Simbólico. Revista Perspectivas Educativas, (5), 325-333.

Romero, A. (1988. Octubre). Educación Popular y Derechos Humanos. Educación y Cultura, (16), 8-13.

Ruiz, A. (2004). Texto Testimonio y Meta texto: El Análisis de Contenido en la Educación. La Practica Investigativa en ciencias Sociales, (8), 41-58.

Torquemada, A.D. (2007. Septiembre). La Práctica Educativa de los Derechos Humanos. Eikasia. Revista de Filosofía, (13), 181-204.

Vázquez, O. 2011. Julio/Septiembre). La Practica de los Derechos Humanos en la Escuela. Aula Urbana, (81), 5-7.

Zafra, D. (1988. Octubre). La educación y Los Derechos Humanos. Educación y Cultura, (16), 31-33.

Zuluaga, L.M. Peláez, P. Guerrero, V. \& Gaviria, Z. (2014) Formación Política y Ciudadana: Ojo de Tingua. Aula Urbana, (92), 8.

\section{Documentos Institucionales y Normas.}

Colombia (2015), Constitución Política, Bogotá, Corte Constitucional.

Instituto Interamericano de Derechos Humanos. (2002). I Informe Interamericano de la Educación en Derechos Humanos. Recuperado, 5 Octubre de 2015. www.iidh.ed.cr/multic/WebServices/Files.ashx?fileID=6114.

Instituto Interamericano de Derechos Humanos. (2003). II Informe Interamericano de la Educación en Derechos Humanos. Recuperado, 5 Octubre de 2015. www.iidh.ed.cr/multic/WebServices/Files.ashx?fileID=6114.

Instituto Interamericano de Derechos Humanos. (2004). III Informe Interamericano de la Educación en Derechos Humanos. Recuperado, 5 Octubre de 2015. www.iidh.ed.cr/multic/WebServices/Files.ashx?fileID=6114.

Instituto Interamericano de Derechos Humanos. (2005). IV Informe Interamericano de la Educación en Derechos Humanos. Recuperado, 5 Octubre de 2015. www.iidh.ed.cr/multic/WebServices/Files.ashx?fileID=6114.

Instituto Interamericano de Derechos Humanos. (2006). V Informe Interamericano de la Educación en Derechos Humanos. Recuperado, 5 Octubre de 2015. www.iidh.ed.cr/multic/WebServices/Files.ashx?fileID=6114. 
Instituto Interamericano de Derechos Humanos. (2007). VI Informe Interamericano de la Educación en Derechos Humanos. Recuperado, 5 Octubre de 2015. www.iidh.ed.cr/multic/WebServices/Files.ashx?fileID=6114

Instituto Interamericano de Derechos Humanos. (2008). VII Informe Interamericano de la Educación en Derechos Humanos. Recuperado, 5 Octubre de 2015. www.iidh.ed.cr/multic/WebServices/Files.ashx?fileID=6114

Instituto Interamericano de Derechos Humanos. (2009). VIII Informe Interamericano de la Educación en Derechos Humanos. Recuperado, 5 Octubre de 2015. www.iidh.ed.cr/multic/WebServices/Files.ashx?fileID=6114

Instituto Interamericano de Derechos Humanos. (2010). IX Informe Interamericano de la Educación en Derechos Humanos. Recuperado, 5 Octubre de 2015. www.iidh.ed.cr/multic/WebServices/Files.ashx?fileID=6114.

Instituto Interamericano de Derechos Humanos. (2011). X Informe Interamericano de la Educación en Derechos Humanos. Recuperado, 5 Octubre de 2015. www.iidh.ed.cr/multic/WebServices/Files.ashx?fileID=6114

Ley 1098. Diario Oficial de la Republica de Colombia. Bogotá. Colombia, 8 de Noviembre de 2006.

Ley 1732. Diario Oficial de la Republica de Colombia. Bogotá. Colombia, 1 de Septiembre de 2014.

Organización Internacional del trabajo OIT. (2005) Convenio N 169 de la OIT Sobre los Pueblos Indignes y Tribales. Recuperado 10 de Mayo de 2016. www.ilo.org/americas/publicaciones/WCMS_213175/lang--es/index.htm.

Organización de las Naciones Unidas para la Educación la Ciencia y la Cultura UNESCO (2008). Declaración Universal de los Derechos Humanos. Recuperado 8 de mayo de 2016. unesdoc.unesco.org/images/0017/001790/179018m.pdf

Organización de las Naciones Unidad ONU (1965) Convención Internacional sobre la Eliminación de todas las Formas de Discriminación Racial. Recuperado en 9 mayo de 2016. www.ohchr.org > OHCHR > Español > Interés profesional.

Organización de las Naciones Unidad ONU (1990) Directrices de las Naciones Unidas para la prevención de la delincuencia juvenil. Recuperado en 10 de mayo de 2016. www.ohchr.org > OHCHR > Español > Interés profesional

Organización de las Naciones Unidad ONU (1984) Convención contra la Tortura y Otros Tratos o Penas Crueles, Inhumanos o Degradantes. Recuperada en 9 de mayo de 2016. www.ohchr.org > OHCHR > Español > Interés profesional

\section{Tesis de Grado.}


Carvajal, A. Fajardo, L.A. Pedraza, M.C. (2008). El Discurso Pedagógico en Colombia: Análisis del Discurso de algunos Intelectuales y sus Interpretaciones Frente al Discurso Oficial en Competencias en los Últimos 25 Años. (Tesis de Maestría) Universidad de la Salle. Bogotá. Colombia.

Olarte, T. (2008). Estado política de Seguridad y Derechos Humanos en Colombia1978-1982 y 2002-2006. (Tesis de Especialización) Escuela Superior de Administración Pública. Bogotá. Colombia.

Rodríguez, D.G. (2015) Tres experiencias para pensar la Educación en Derechos Humanos en Colombia (tesis de Maestría) Universidad del Rosario. Bogotá. Colombia.

Sánchez, L.Y. (2014). La Educación Social: Una Apuesta desde el que Hacer del Trabajador Social (Tesis de Maestría). Universidad de San Buenaventura. Cali. Colombia. Universidad La Gran Colombia. Armenia. Colombia.

\section{Webgrafria.}

Berstein, B. (1984). Hacia una Teoría del discurso Pedagógico. Recuperado. 10 de Mayo de 2016. www.pedagogica.edu.co/storage/rce/articulos/15_08ens.pdf

Freire, P. (2011) definición de escuela. Recuperado 10 de Junio de 2016. Paradigma educativo 35.blogspot.com.

Illich, I. (1985). La Sociedad Desescolarizada. Recuperado 9 de mayo de 2016. www.mundolibertario.org/archivos/.../IvnIllich_lasociedaddesescolarizada.pdf.

Magendzo, A. (2002) Pedagogía Critica y Educación en Derechos Humanos. Recuperado. 10 de Mayo de 2016. www.redacademica.edu.co/.../anexo_7-11_pedagogia-critica-yeducacionen-derechos.

Tünnermann, C. (1999). Educación en Derechos Humanos en los sistemas educativos. $\begin{array}{llllll}\text { Recuperado } & 9 & \text { de } & \text { Mayo } & \text { de } & 2016 .\end{array}$ www.dhnet.org.br/educar/mundo/a_pdf/bernheim_edh_sistemas_educactivos.pdf.

Vázquez, G. (2010). Hacia una Valoración Positiva del Concepto de Error. Recuperado 9 de Mayo de 2016. marcoele.com/descargas/navas/07.vazquez.pdf. 